\title{
Regional Convergence and Aggregate Business Cycle in the United States
}

\author{
STEFANO MAGRINI*, MARGHERITA GEROLIMETTO* and HASAN ENGIN DURAN† \\ *Università Ca' Foscari Venezia, SSE (Advanced School of Economics in Venice), Department of Economics, Cannaregio, 873, \\ I-30121Venice, Italy.Emails: s.magrini@unive.it and margherita.gerolimetto@unive.it \\ †Izmir Institute of Technology, City and Regional Planning Department, IYTE Gülbahçe Kampüsü, 35430, Urla - Izmir, \\ Turkey.Email: enginduran@iyte.edu.tr
}

(Received June 2011: in revised form December 2012)

Magrini S., Gerolimetto M. and Engin Duran H. Regional convergence and aggregate business cycle in the United States, Regional Studies. The existing literature on convergence largely ignores the effect of aggregate fluctuations on the evolution of income disparities. However, if regional disparities follow a distinct cyclical pattern in the short run, the period of analysis should be chosen with great care to avoid distortions in the results. By analysing convergence among forty-eight conterminous US states through the distribution dynamics approach, it is shown that these distortions could be quite sizeable. Moreover, when convergence is analysed over an appropriate period that includes only complete cycles (1989-2007), results show that regional disparities exhibit a pro-cyclical behaviour and that the underlying long-run tendency is towards divergence.

Convergence Regional disparities Business cycle Distribution dynamics

Magrini S., Gerolimetto M. and Engin Duran H. 美国的区域趋同与总量经济週期，区域研究。有关趋同的既有文 献, 多半忽略收入差距评估中的总量波动。但若区域差异在短期内会随着显着的週期模式而波动, 那麼则必须谨慎选 择分析的时程, 以避免结果被扭曲。本研究透过分佈动态取径, 分析美国四十八个相互连接州的趋同, 显示上述的扭 曲问题可能相当巨大。此外，当在一个仅包含完整週期（1989 至 2007 年）的适当时程中分析趋同时，分析结果显示 区域差距展现出正向週期性行为，而潜在的长期趋势则倾向分歧。

\section{趋同 区域差距 经济週期 分佈动态}

Magrini S., Gerolimetto M. et Engin Duran H. La convergence régionale et le cycle économique global aux États-Unis, Regional Studies. Dans une large mesure, la documentation actuelle sur la convergence ne tient pas compte de l'effet des fluctuations globales sur le développement des inégalités de revenu. Cependant, si les inégalités régionales présentent des tendances cycliques très nettes à court terme, il faut déterminer la période à étudier avec prudence afin d'éviter des résultats erronés. En analysant la convergence à partir de quarante-huit états contigus aux États-Unis par moyen de la façon dynamiques de distribution, on montre que ces résultats erronés pourraient s'avérer assez importants. En outre, quand on analyse la convergence sur une période appropriée qui ne comprend que des cycles économiques complets (entre 1987 et 2007), les résultats laissent voir que les inégalités régionales présentent un comportement procyclique et que la tendance sous-jacente à long terme est à la divergence.

Convergence Inégalités régionales Cycle économique Dynamiques de distribution

Magrini S., Gerolimetto M. und Engin Duran H. Regionale Konvergenz und kumulierte Geschäftszyklen in den USA, Regional Studies. In der vorhandenen Literatur über Konvergenz wird die Auswirkung von kumulierten Fluktuationen auf die Entwicklung von Einkommensdisparitäten weitgehend ignoriert. Wenn jedoch die regionalen Disparitäten kurzfristig einem ausgeprägt zyklischen Muster folgen, sollte die analysierte Periode sorgfältig ausgewählt werden, um eine Verzerrung der Ergebnisse zu vermeiden. Durch eine Analyse der Konvergenz von 48 angrenzenden Bundesstaaten der USA mit Hilfe des Distributionsdynamik-Ansatzes wird nachgewiesen, dass diese Verzerrungen recht erheblich ausfallen könnten. Darüber hinaus geht bei einer Analyse der Konvergenz während eines angemessenen Zeitraums, der nur vollständige Zyklen umfasst (19892007), aus den Ergebnissen hervor, dass die regionalen Disparitäten ein prozyklisches Verhalten aufweisen und dass die zugrundeliegende langfristige Tendenz zur Divergenz hin verläuft.

Konvergenz Regionale Disparitäten Geschäftszyklus Distributionsdynamik

Magrini S., Gerolimetto M. y Engin Duran H. Convergencia regional y el ciclo comercial agregado en los Estados Unidos, Regional Studies. En la actual bibliografia sobre la convergencia se ignora en gran medida el efecto de las fluctuaciones agregadas en lo que respecta a la evolución de las desigualdades de ingresos. Sin embargo, si las desigualdades regionales siguen a corto plazo un 
patrón cíclico destacado, habría que elegir el periodo de análisis con sumo cuidado para evitar distorsiones en los resultados. Al examinar la convergencia entre cuarenta y ocho Estados limítrofes de los Estados Unidos mediante un enfoque sobre las dinámicas de distribución, demostramos que estas desigualdades podrían ser bastante considerables. Además, si analizamos la convergencia de un periodo apropiado incluyendo solamente ciclos completos (1989-2007), los resultados indican que las desigualdades regionales muestran un comportamiento procíclico y que la tendencia subyacente a largo plazo va hacia la divergencia.

Convergencia Desigualdades regionales Ciclo comercial Dinámicas de distribución

JEL classifications: C14, E32, O40, R10

\section{INTRODUCTION}

The vast majority of studies on convergence among national and sub-national economic systems implicitly adopts a long-run perspective as it relates empirical findings from the analysed period to the long-run predictions of a variety of theoretical models. Very few studies have instead adopted a different viewpoint and analysed the evolution of income disparities among a set of economies in relation to the aggregate business cycle. In most cases, regional disparities are found to move in a pro-cyclical fashion, therefore increasing during expansion periods and diminishing during slowdowns. Some examples are Azzoni (2001), who analysed per capita gross domestic product (GDP) growth and disparities across Brazilian states between 1939 and 1995; DEWHURST (1998), who analysed regional household income disparities among sixty-three UK counties between 1984 and 1993; CHATTERJi and DeWhurst (1996), who studied per capita GDP disparities across English and Welsh counties and Scottish regions between 1977 and 1991; PETRAKOS and SARATSIS (2000), who analysed per capita GDP inequalities among Greek prefectures between 1970 and 1995; TERRASI (1999), who studied convergence in per capita GDP among twenty Italian regions between 1953 and 1993; Petrakos et al. (2005), who analysed per capita GDP disparities across eight European Union countries between 1960 and 2000; and PIKE et al. (2012), who studied the evolution of disparities in per capita disposable household income across UK NUTS-1 (Nomenclature des Unités Territoriales Statistiques) regions between 1984 and 2007. In fewer instances, authors instead reported the presence of counter-cyclical disparities. This is the case for Pekkala (2000) and Kangasharju and Pekkala (2004), who investigated per capita GDP disparities across small-scale Finnish sub-regions, respectively, in the 1988-1995 and 1988-2000 periods; and for BOUvet (2010), who studied the evolution of per capita GDP inequalities among 197 NUTS-2 regions belonging to thirteen European Union countries between 1977 and 2003. Furthermore, QUAH (1996) reported some evidence of counter-cyclical behaviour of per capita personal income disparities while analysing US states between 1982 and 1990. Finally, DURAN (2014), by applying time-series techniques on per capita personal income data for the forty-eight coterminous US states between 1969 and 2008, found that disparities moved either pro- or counter-cyclically depending on the period of analysis. In particular, the analysis showed that the switch form counter to procyclicality that had occurred since the beginning of the 1990s was largely a consequence of differences in the timing with which the business cycle was felt across US states.

From a theoretical point of view, several interpretations have been offered for the pro-cyclical behaviour of regional disparities. Petrakos et al. (2005) and PetRAKOS and SARATSIS (2000) explained this behaviour by referring to BERRY (1988) who, sharing Myrdal's view (MYRDAL, 1957) on the spatially cumulative nature of growth, suggested that leading regions were in a better position to take advantage of the opportunities generated by an economic boom. In particular, according to this view, expansion phases begin in more developed and metropolitan areas where agglomeration and market size create a lead over other regions, thus leading to an increase in regional disparities (PETRAKOs et al., 2005). The opposite applies in downturns, during which more developed and metropolitan areas tend to suffer more (Petrakos and SARAtSis, 2000). A somewhat different perspective is offered by RODRÍGUEZ-POSE and FRATESI (2007) who concentrated on the concept of sheltered regions, that is, isolated economies which are mostly dependent on the agriculture sector, government transfers and public employment. Based on this view, sheltered regions do not keep up with the rest of the aggregate economy and do not use their potential for convergence during the expansion periods. By contrast, during downturns they do not suffer as much as other regions and, therefore, tend to reduce their gap with respect to richer ones. In the same vein, Azzoni (2001) stated that richer regions are better prepared to face growing demand during expansions due to the presence of more dynamic sectors in their production structure, a claim that is fully consistent with the explanation of different timing and amplitudes of cyclical waves provided by AIrov (1963) and VAN DUIJN (1973). On the opposite side, Pekkala's (2000) and Kangasharju and PekkaLA's (2004) explanation of counter-cyclical disparities in Finland hinged upon the equilibrating role played by 
labour mobility and the effectiveness of regional policies. In particular, these authors noted that during expansions there is a higher degree of mobility and that these workers tend to migrate mainly towards developed sub-regions, thus contributing to reduce per capita income disparities. Conversely, inequalities increase during slowdowns as workers' migration stagnates. In addition, regional policies have had a more cohesive effect during the upswing years of the economic cycle due to a relatively more abundant amount of resources devoted to pursuing regional equality with respect to slowdown periods.

Shedding light on this issue is of crucial importance for empirical convergence analysis. To the extent that regional income disparities follow a distinct cyclical pattern in the short-run, moving either pro- or counter-cyclically, the choice of the period of analysis becomes a delicate matter: when the chosen period includes an unequal number of expansions and downturns, the over-represented dynamics might introduce a bias in the results. For instance, suppose regional disparities follow a pro-cyclical pattern. Then, if the period of analysis contains less (more) contraction phases than expansions, results might be misleading as they would derive from an over-representation of dynamics towards divergence (convergence). It is only when the period of analysis contains an equal number of expansions and downturns that the analyst might be able to understand whether convergence or divergence is occurring.

The fact that the choice of the period of analysis might spuriously affect the empirical results has already been suggested by a few authors (MAGRINI, 1999; Peknala, 2000; Petrakos et al., 2005); none of them, however, has ever attempted to show explicitly how large the introduced distortion could actually be. This paper is precisely aimed at shedding light on this issue. At the same time, given that misleading results can arise unless cyclical effects on convergence are taken into consideration, convergence in per capita personal income among forty-eight US states is analysed over a specifically chosen period (1989-2007) that stretches between two peaks of the aggregate business cycle.

From a methodological point of view, the continuous state-space distribution dynamics approach first introduced by QUAH (1997) is opted for. Following the work of BAUMOL (1986), BARRO and SALA-IMARTIN (1991, 1995), MANKIW et al. (1992), and SALA-I-MARTIN (1996), most empirical research on convergence has adopted the so-called regression approach to investigate whether $\beta$-convergence occurs, where $\beta$ is the generic notion for the coefficient on the initial income variable in the growth-initial level regressions and relates to the speed with which a representative economy approaches its steady-state growth path within the neoclassical growth model. This approach, however, has stimulated the critical attention of many scholars who have emphasized its limitations and proposed alternatives (for an account of this literature see, among others, DURLAUF and QUAH, 1999; Temple, 1999; Islam, 2003; Magrini, 2004, 2009; Abreu et al., 2005; and Durlauf et al., 2005). Sharing the view that the regression approach presents several critical inadequacies, this study therefore follows the distribution dynamics approach, a non-parametric approach that rather than focusing on the representative economy, concentrates on the evolution of the entire cross-sectional distribution and describes both the change in its external shape and the intra-distribution dynamics through the estimate of a stochastic kernel.

Previous applications of the distribution dynamics approach to US data provide ambiguous results. On the one hand, a few studies report evidence of income convergence across US states. For instance, QUAH (1997) depicted a pattern of convergence in per capita personal income among the states between 1948 and 1989 and noted that the ergodic distribution was unimodal, in sharp contrast with the club convergence result found while analysing income distribution among world countries. Similar findings were also obtained by JOHNSON (2000), who concentrated on the slightly more extended period 1948-1993 and found again a unimodal ergodic distribution; and by HAMMOND and Thompson (2002), who, resorting to the discrete state-space distribution dynamics approach, reported the presence of a strong tendency towards convergence in per capita personal income of the states during the 1929-1999 period. In addition, Yамамото (2008) studied convergence dynamics in per capita personal income across both states and counties between 1957 and 2005. For both sets of spatial units a convergence result was reported as the corresponding ergodic distributions were unimodal; however, this tendency towards convergence appeared to be stronger across counties. WANG (2004) studied disparities in per capita personal income across fifty-nine provinces and states in Canada and the United States and showed that they strongly decreased in the 1950-1970 period, kept almost unchanged in the 1971-1990 period, while exhibiting a clear increase in the 1991-2000 period. Tsionas (2000) analysed the evolution of the distribution of per capita gross state product (GSP) between 1977 and 1996 by fitting finite normal mixtures by maximum likelihood methods and reported the existence of a strong persistence in regional differences as mixture means and standard deviations tended to move together. Finally, DiCECIO and GASCON (2010) reported evidence of polarization. More specifically, they analysed per capita personal income convergence across states, metropolitan and non-metropolitan portions of the states between 1969 and 2005 and found bimodal ergodic distributions for all sets. Moreover, they showed that while the metropolitan portions of the states converged towards the national 
average, non-metropolitan portions converged to lower incomes.

The paper is organized as follows. In the second section, the US business cycle is estimated using Hodrick-Prescott (HP) filtering and the timing of the phases is then established using the Bry-Boschan algorithm. The third section provides a description of the distribution dynamics approach adopted here, while the convergence analysis is implemented in the fourth section. The fifth section concludes the study.

\section{US BUSINESS CYCLE AND REGIONAL DISPARITIES}

The analysis starts with an estimate of the US business cycle as well as of the turning points within this cycle. As a preliminary, two decisions must be made: the income variable to be employed and the time period to be examined. With reference to the income variable, it must be considered that, generally speaking, two options are available at a regional level in the United States: GDP and personal income. As is common practice among studies focusing on the United States, the latter was chosen here for two main reasons. On the one hand, in order to identify correctly the phases of the cycle and to produce a meaningful analysis, a relatively high frequency of data (at least quarterly) is needed and this is only available for personal income. On the other hand, due to the Standard Industrial Classification (SIC)-North American Industry Classification System (NAICS) switch, only few observations on GSP are actually available for recent years.

It must, however, be stressed that studies focusing on other countries generally employ per capita GDP. For this reason, it is worth spelling out the main differences between these two variables in order to understand whether they should exhibit different patterns in regional disparities along the cycle. In short, personal income is equal to GDP - less: capital depreciation, corporate profits with inventory valuation and capital consumption adjustments, contributions for government social insurance, domestic net interest and miscellaneous payments on assets, net business current transfer payments, current surplus of government enterprises, and undistributed wage accruals; plus: net income from assets abroad, personal income receipts on assets, and personal current transfer receipts. Among these, the entry that more evidently moves in relation to the cycle is 'personal current transfer receipts', which act in such a way as to smooth out cyclical waves with respect to GDP during downturns. Essentially for this reason, the present study adopts personal income per capita net of personal current transfer receipts. Consequently, this entry should play no role in explaining the differences between GDP and personal income series and any remaining difference should then be attributed to: globalization patterns; indirect and corporate taxes, capital depreciation and undistributed corporate profits; and differences in the price indexes employed for deflating the series (LABONTE, 2006). All in all, the role that these elements should play in explaining different patterns in disparities along the cycle is rather uncertain and the variable employed here is therefore not expected to bias the results in any particular direction.

As far as the time period is concerned, DURAN (2014) found that income disparities across US states switch from counter to pro-cyclical between the end the 1980s and the beginning of the 1990s and Duran ascribed this to a combination of a process of structural transformation towards a knowledge-based 'new economy' and a change in the direction of factor flows. For the purpose of the present analysis, it is essential to focus on a period in which disparities move unambiguously either pro- or counter-cyclically; hence, it is a rather natural choice to select the period stretching between 1989:Q1 and 2007:Q4 since inequalities follow clearly a pro-cyclical evolution.

Moving now to the business cycle, it must be emphasized that attention is concentrated here on deviation cycles, that is, fluctuations of the economy around its deterministic trend. As suggested by several authors (for example, ZARNOWITZ and OZYILDIRIM, 2006; HODRICK and PRESCOTT, 1997) due to a decreased output volatility after the Second World War in the United States, deviation cycles are more useful in recent periods than classical cycles as the former include more fluctuations with adequate duration and amplitude. From a technical point of view, the Hodrick-Prescott (HP) filter (HODRICK and PRESCOTT, 1997) is therefore used to de-trend US per capita real personal income net of current transfer receipts, ${ }^{1}$ and the Bry-Boschan algorithm (BRY and BOSCHAN, 1971), as reorganized by HARDING and PAGAN (2003) for quarterly data, is used to detect turning points. ${ }^{2}$ Table 1 summarizes the identified turning points for the US economy between 1989 and 2007, while Fig. 1 presents expansions and slowdowns. Specifically, it is possible to identify four peaks and three troughs which, as anticipated, will be used for choosing the time span of the periods in the analysis of convergence.

Table 1. US turning points (Hodrick-Prescott cycle)

\begin{tabular}{ll}
\hline Dates & Peak or trough \\
\hline 1989:Q1 & Peak \\
1991:Q4 & Trough \\
1994:Q4 & Peak \\
1995:Q4 & Trough \\
2000:Q1 & Peak \\
2007:Q2 & Trough \\
\hline
\end{tabular}




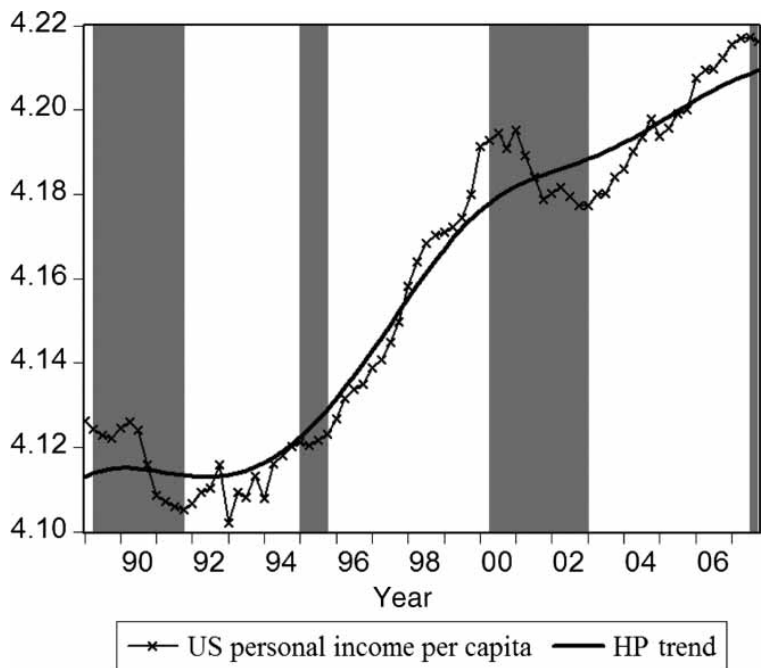

Fig. 1. US personal income and cycle phases, 1989-2007 Note: Grey-shaded areas represent slowdowns identified using the Bry-Boschan algorithm on Hodrick-Prescott (HP)-filtered data

It should be pointed out that several alternative methods to identify the cycle and its turning points are available in the literature. Here the HP filter has been opted for due to its simplicity and widespread use, and the Bry-Boschan algorithm also for its non-parametric nature; at the same time, in order to evaluate the sensitivity of the results, a few alternatives have also been employed. As far as the identification of the cycle is concerned, DURAN (2014) found very similar results by applying both the HP filter and the one proposed by CHRISTIANO and FitzGerald (2003) to data on the US states over a comparable period. Hence, to add further evidence on this issue, a third well-known technique is employed in this paper: the Baxter-King filter (BAXTER and KING, 1999). A second set of turning points has therefore been obtained by applying the Bry-Boschan algorithm to the Baxter-King-filtered data. Finally, the official turning points set declared by the National Bureau of Economic Research (NBER) ${ }^{3}$ was also considered. These alternative sets of turning points are reported in Table 2, while corresponding results from the distribution dynamics analysis are reported in the figures given in Appendices $\mathrm{A}$ and $\mathrm{B}$.

Fig. 2 displays the evolution of some inequality measures calculated using per capita personal income data for the forty-eight coterminous states in relation to the timing of the US business cycle phases. A wide variety of inequality measures exist in the literature and it is known that the choice of instrument may affect the results (COWELl, 2008; Firebaugh, 2003; Portnov and Felsenstein, 2010). For this reason, attention is focused on three among the most commonly adopted measures, namely, the coefficient of variation, the population-weighted coefficient of
Table 2. Alternative US turning points

\begin{tabular}{lllll}
\hline & & & \multicolumn{2}{c}{$\begin{array}{c}\text { National Bureau of Economic } \\
\text { Research (NBER) } \\
\text { announcements }\end{array}$} \\
\cline { 1 - 1 } \cline { 5 - 5 } Dates & Peak or trough & & Dates & Peak or trough \\
\hline 1991:Q3 & Trough & & 1990:Q3 & Peak \\
1992:Q3 & Peak & & 1991:Q1 & Trough \\
1993:Q3 & Trough & & 2001:Q1 & Peak \\
1994:Q3 & Peak & & 2001:Q4 & Trough \\
1997:Q2 & Trough & & 2007:Q4 & Peak \\
1998:Q3 & Peak & & & \\
1999:Q2 & Trough & & & \\
2000:Q3 & Peak & & & \\
2002:Q1 & Trough & & & \\
2004:Q3 & Peak & & & \\
2005:Q2 & Trough & & & \\
2007:Q3 & Peak & &
\end{tabular}

variation, and the Theil Index. All these measures appear to suggests that income disparities tend to move in a pro-cyclical fashion, with the only exception of a period of four years stretching from 1992:Q1 to 1995:Q4. In other words, pro-cyclical disparities appear to dominate the period of analysis as they can be recognized over more than $75 \%$ of the period of analysis.

Having estimated the turning points in the US cycle and noted that cross-sectional disparities in per capita income tend to move in a pro-cyclical way, it is now possible to turn one's attention to the analysis of

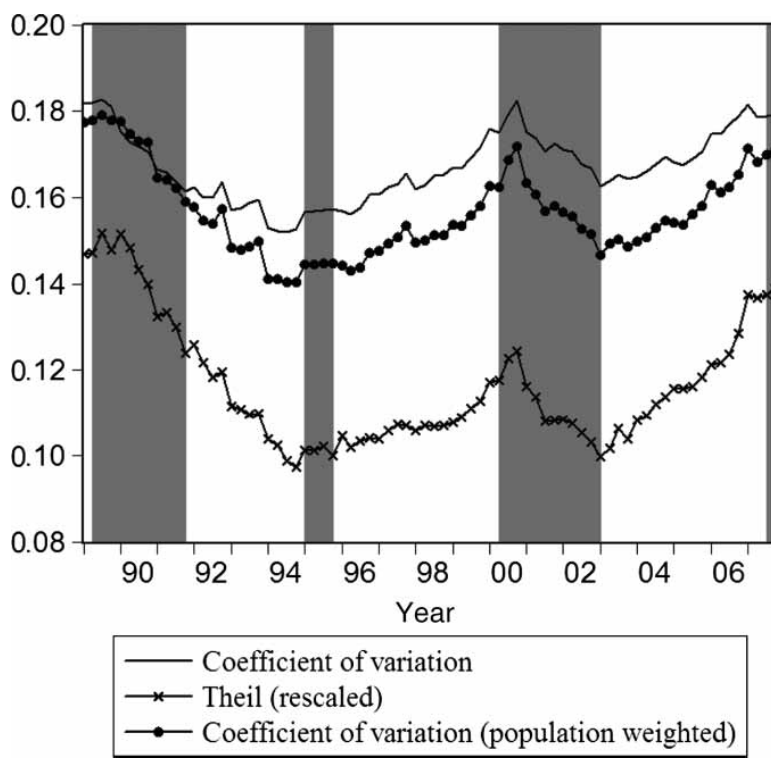

Fig. 2. US business cycle and regional disparities, 19892007

Note: Grey-shaded areas represent slowdowns identified using the Bry-Boschan algorithm on Hodrick-Prescott (HP)-filtered data 
convergence providing, first, a few technical details on the adopted methodology.

\section{DISTRIBUTION DYNAMICS APPROACH}

As motivated in the first section, convergence is analysed by adopting the distribution dynamics approach whose distinctive feature is to examine directly the evolution of the cross-sectional distribution of per capita income.

Let the random variables $X$ and $Y$ represent per capita income (relative to group average) of a group of $n$ economies at time $t$ and $t+s$, respectively. Now, let $F(X)$ and $F(Y)$ represent the corresponding distributions and assume that each admits a density denoted, respectively, with $f(X)$ and $f(Y)$. Next, assuming that the dynamics of $f(\bullet)$ can be modelled as a first-order process, the density at time $t+s$ is given by:

$$
f(Y)=\int_{-\infty}^{\infty} f(Y \mid X) f(X) \mathrm{d} X
$$

where $f(Y \mid X)$ is the stochastic kernel, effectively a conditional density function, mapping the density at time $t$ into the density at time $t+s$. The stochastic kernel is essentially the element that allows one to perform the analysis of convergence within this approach: it provides information both on the evolution of the external shape of the income distribution and on intra-distributional dynamics, that is, on the movement of the economies from one part of the distribution to another between time $t$ and time $t+s$. Convergence can hence be
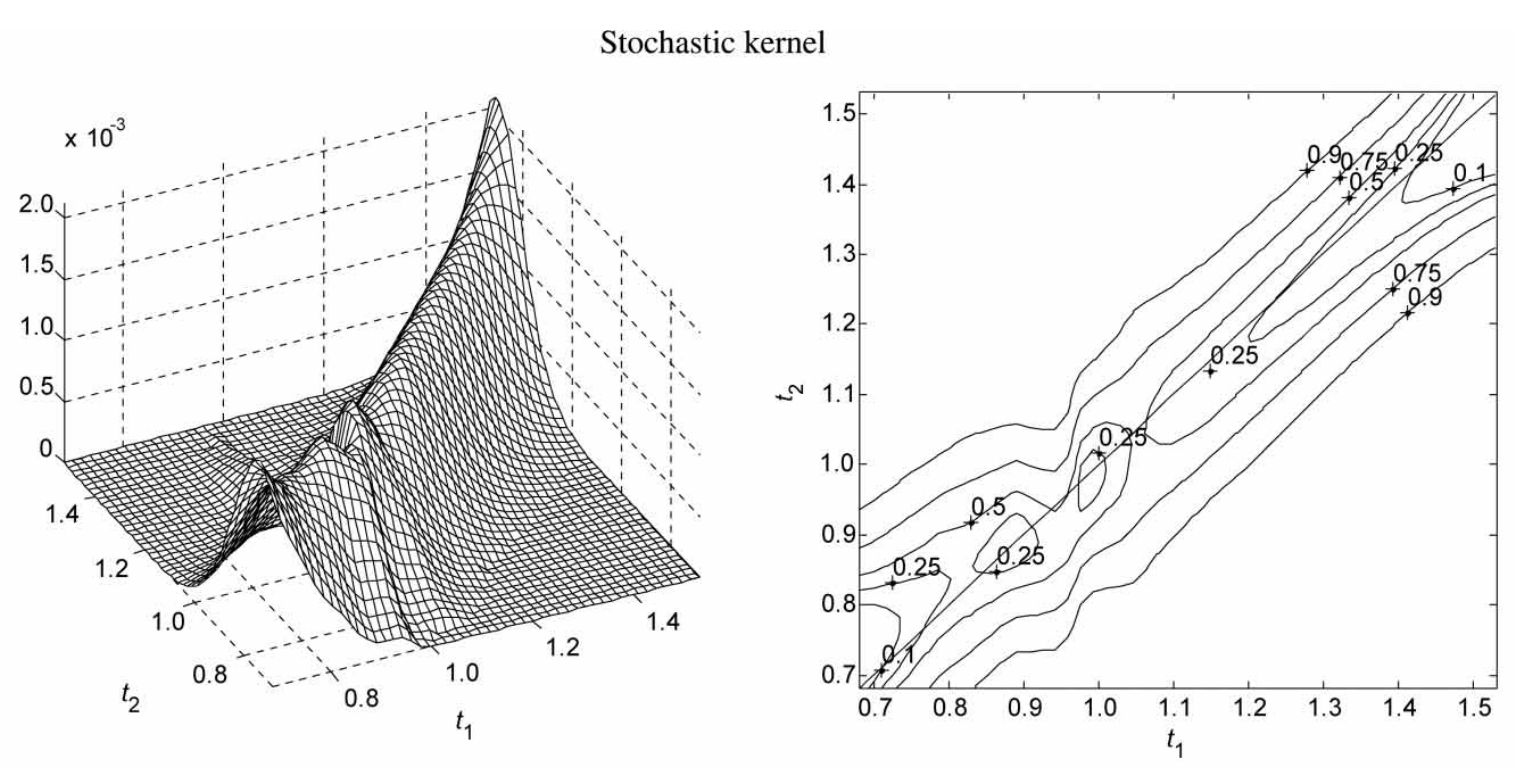

Initial $\left(t_{1}\right)$
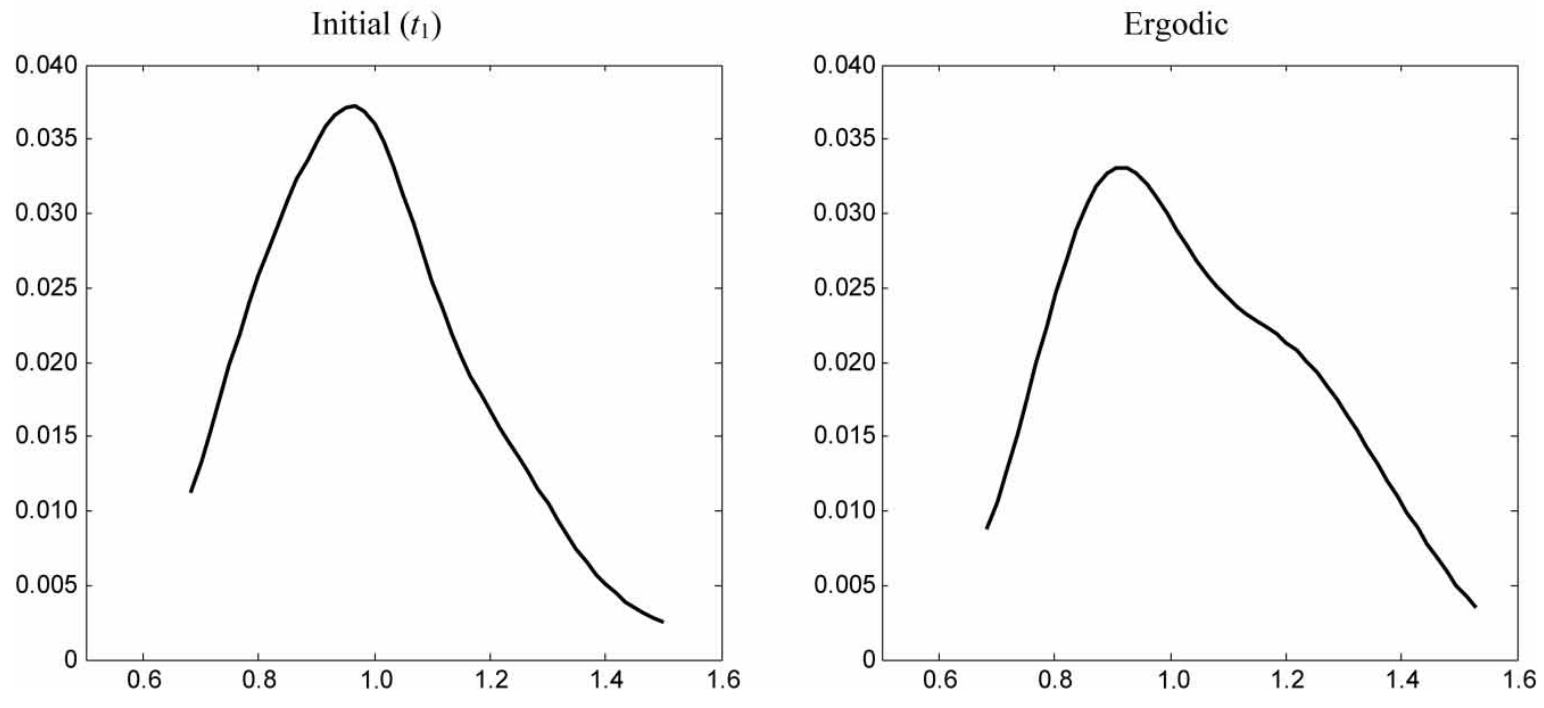

Fig. 3. Distribution dynamics: peak to peak: 1989:Q1-2007:Q2

Note: Estimates were obtained using normal-scale bandwidths (SILVERMAN, 1986) and a Gaussian kernel. A local linear estimate of the mean function was employed for the mean bias adjustment (HYNDMAN et al., 1996). In the plots, $t_{1}$ refers to the initial moment(s) of the transition period(s) 
analysed directly from the shape of a plot of the stochastic kernel estimate or, assuming that the process behind equation (1) follows a time-homogenous Markov process, by comparing the shape of the initial distribution with the stationary (or ergodic) distribution which is the limit of $f(Y)$ as $s \rightarrow \infty$.

One possible way to do this is through the discretization of the income space whereby the density estimates in equation (1) can be obtained via a very simple nonparametric density estimator: the histogram. As a consequence of discretization, the cross-sectional distributions become probability vectors; for the same reason, the stochastic kernel simplifies into a transition probability matrix. Despite its simplicity, the histogram is rather statistically inefficient compared with other non-parametric density estimators. Moreover, as commonly recognized in the literature, discretizing a continuous process can distort dynamics in important ways (Magrini, 1999; Reichlin, 1999; Bulli, 2001).

Given these critical remarks, a radical alternative is to eschew discretization and retain a continuous income space. ${ }^{4}$ In this case, a common way to obtain an estimate of the stochastic kernel in equation (1) is through the kernel density estimator. In particular, denote by $\left\{\left(X_{1}, Y_{1}\right),\left(X_{2}, Y_{2}\right), \ldots,\left(X_{n}, Y_{n}\right)\right\}$ the sample of size $n$, and by $\left\{\left(x_{1}, y_{1}\right),\left(x_{2}, y_{2}\right), \ldots,\left(x_{n}, y_{n}\right)\right\}$ the observations. The kernel density estimator of $Y$ conditional on $X=x$ is as follows:

$$
\hat{f}(y \mid x)=\sum_{j=1}^{n} w_{j}(x) K_{b}\left(y-Y_{j}\right)
$$

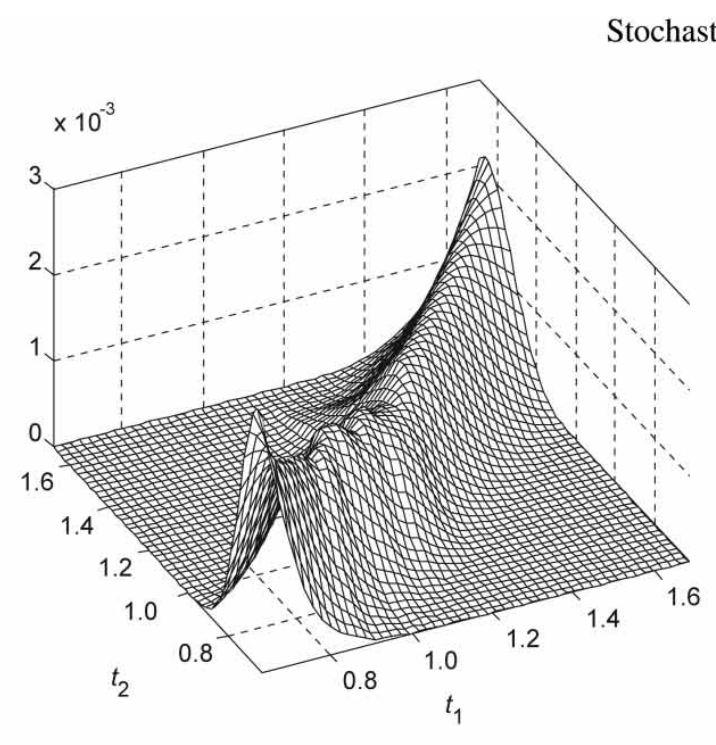

Initial $\left(t_{1}\right)$

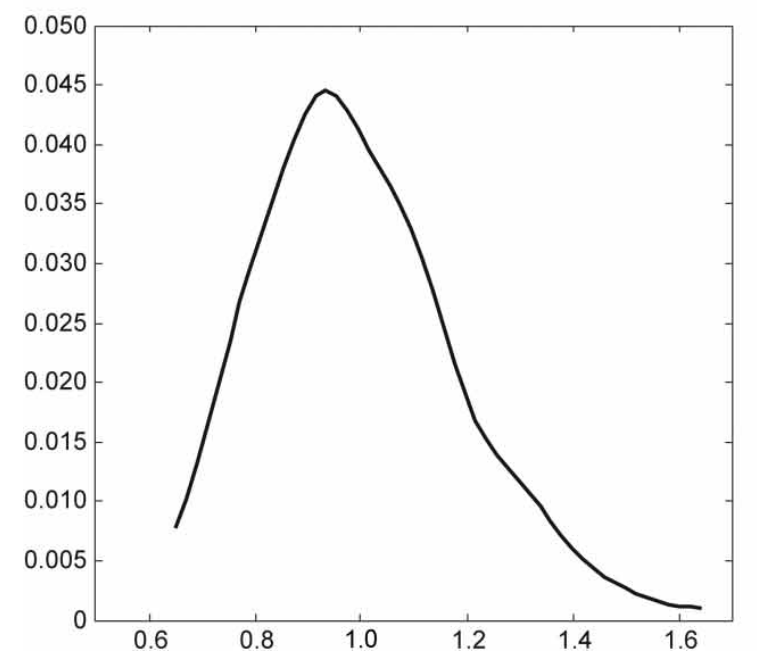

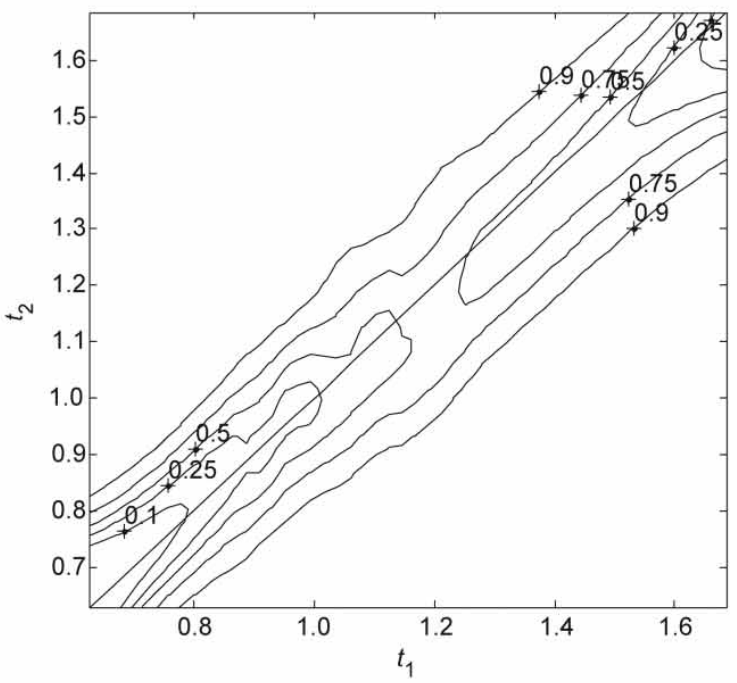

Ergodic

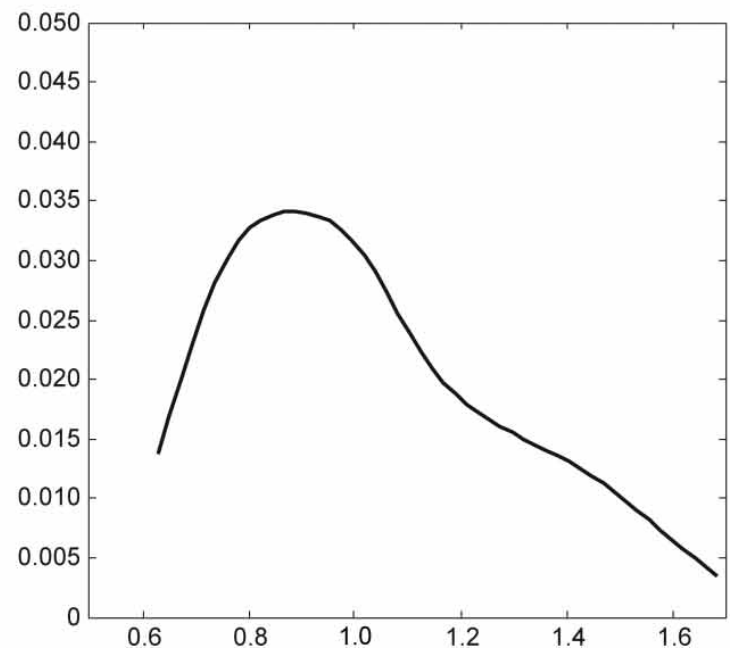

Fig. 4. Distribution dynamics: peak to peak: 1989:Q1-1994:Q4; 1994:Q4-2000:Q1; 2000:Q1-2007:Q2

Note: Estimates were obtained using normal-scale bandwidths (SILVERMAN, 1986) and a Gaussian kernel. A local linear estimate of the mean function was employed for the mean bias adjustment (HYNDMAN et al., 1996). In the plots, $t_{1}$ refers to the initial moment(s) of the transition period(s) 
where:

$$
w_{j}(x)=\frac{K_{a}\left(x-X_{j}\right)}{\sum_{j=1}^{n} K_{a}\left(x-X_{j}\right)}
$$

where $a$ and $b$ are bandwidth parameters which control for the smoothness in the dimensions of $X$ and $Y$, respectively, and:

$$
K_{b}(u)=b^{-1} K\left(\frac{u}{b}\right)
$$

is a scaled kernel function. ${ }^{5}$

Despite its widespread use, however, Hyndman et al. (1996) argued that the estimator in equation (2) might have poor bias properties. To clarify this, denote the conditional mean with:

$$
m(x)=E(Y \mid X=x)
$$

so that:

$$
Y_{j}=\left(X_{j}=x_{j}\right)=m\left(x_{j}\right)+\varepsilon_{j}
$$

where $j=1, \ldots, n$; and $\varepsilon$ is zero mean, independent but not necessarily identically distributed.
An estimate of the conditional mean function $m(x)$ is provided by the mean of the conditional density estimator in equation (2):

$$
\hat{m}(x)=\int Y \hat{f}(y \mid x) \mathrm{d} y=\sum_{j=1}^{n} w_{j}(x) Y_{j}
$$

This estimate has been shown by HyNDMAn et al. (1996) to be equivalent to the Nadaraya-Watson (NADARAYA, 1964; WATSON, 1964), or local constant, regression estimator which is known to be biased on the boundary of the $X$ space and also in the interior. This bias has often be referred to as the mean bias.

To overcome the mean-bias problem, HyNDMAN et al. (1996) developed a new class of conditional density estimators:

$$
\hat{f}^{*}(y \mid x)=\sum_{j=1}^{n} w_{j}(x) K_{b}\left(y-Y_{j}^{*}(x)\right)
$$

where:

$$
Y_{j}^{*}(x)=\hat{m}(x)+e_{j}-\sum_{i=1}^{n} w_{i}(x) e_{i}
$$

with $i=1, \ldots, n$.

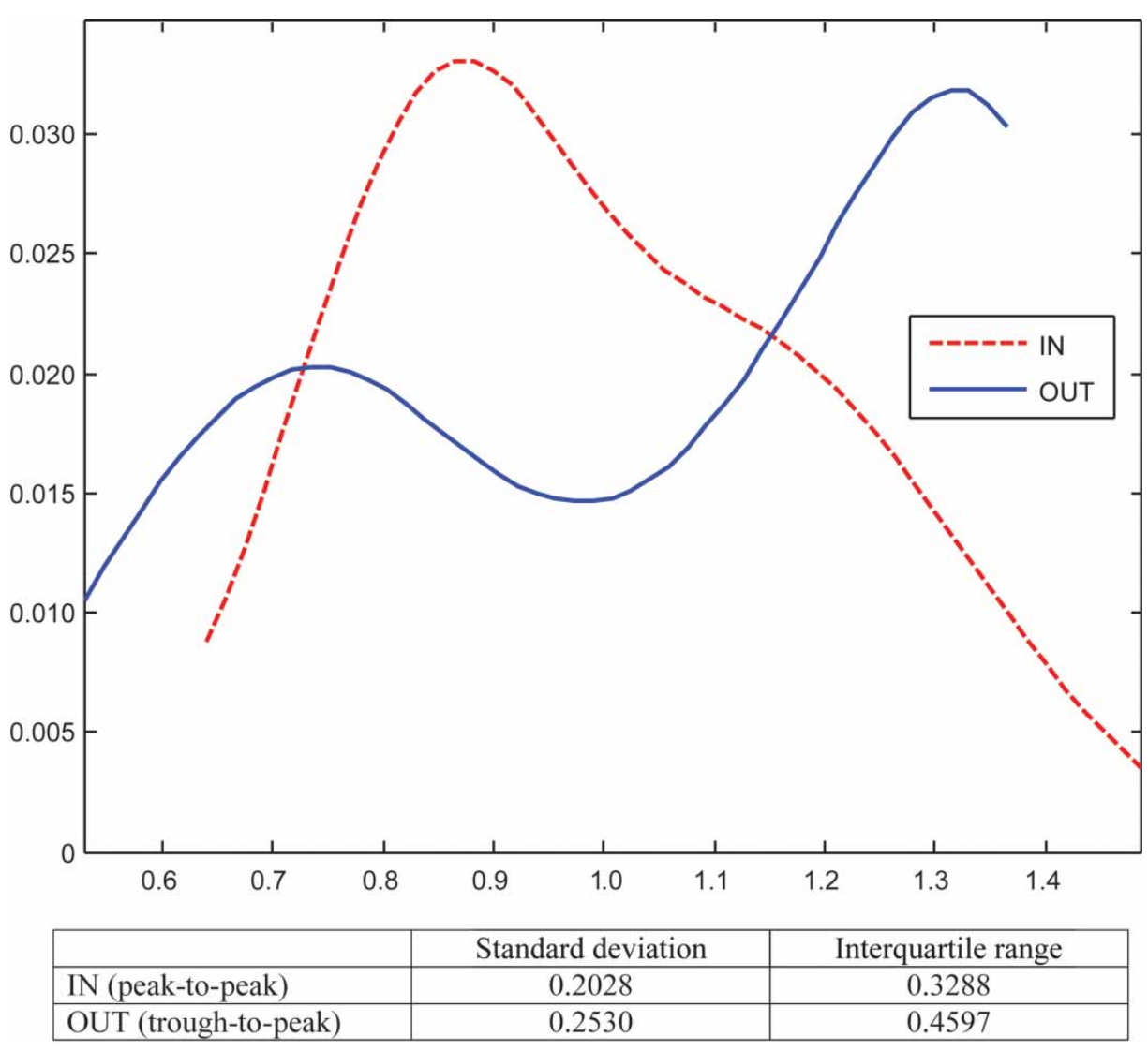

Fig. 5. Comparison between distribution dynamics: peak to peak: 1989:Q1-2007:Q2; and trough to peak: 1991:Q4-2007:Q2 Note: Estimates were obtained using normal-scale bandwidths (SILVERMAN, 1986) and a Gaussian kernel. A local linear estimate of the mean function was employed for the mean bias adjustment (HYNDMAN et al., 1996) 
According to these authors, a lower mean bias can be obtained using an estimator of $m(x)$ with better properties than the Nadaraya-Watson regression estimator. One possibility is to use a local linear estimator (LOADER, 1999):

$$
\begin{aligned}
\hat{m}(x)= & \frac{\sum_{j=1}^{n} K_{a}\left(x-X_{j}\right) Y_{j}}{\sum_{j=1}^{n} K_{a}\left(x-X_{j}\right)} \\
& +\left(x-\bar{X}_{w}\right) \frac{\sum_{j=1}^{n} K_{a}\left(x-X_{j}\right)\left(X_{j}-\bar{X}_{w}\right) Y_{j}}{\sum_{j=1}^{n} K_{a}\left(x-X_{j}\right)\left(X_{j}-\bar{X}_{w}\right)^{2}}
\end{aligned}
$$

where:

$$
\bar{X}_{w}=\frac{\sum_{j=1}^{n} K_{a}\left(x-X_{j}\right) X_{j}}{\sum_{j=1}^{n} K_{a}\left(x-X_{j}\right)}
$$

The mean-bias adjustment proposed by HYNDMAN et al. (1996) is therefore applied in the present analysis and the local linear estimator is used to obtain an estimate of the mean function.

\section{EMPIRICAL RESULTS}

This section reports the results of the empirical analysis of convergence across US states over the entire period spanning from 1989 to 2007.

Initially, coherently with what was previously explained, convergence dynamics between corresponding turning points along the business cycle were analysed. Specifically, focusing on the turning points identified through the Bry-Boschan algorithm on HP-filtered personal income quarterly data, the entire period of the analysis was defined as the period running from the peak of 1989:Q1 to the peak of 2007:Q2. ${ }^{6}$ Convergence, therefore, was studied both using a single transition between the just-mentioned peaks and using three transitions, thus making use of two additional intermediate peaks (1994:Q4 and 2000:Q1). Hereafter, this type of analysis is referred to as the analysis 'in phase'.

Subsequently, it is shown how short-run dynamics can alter the picture by distorting the outcome of the

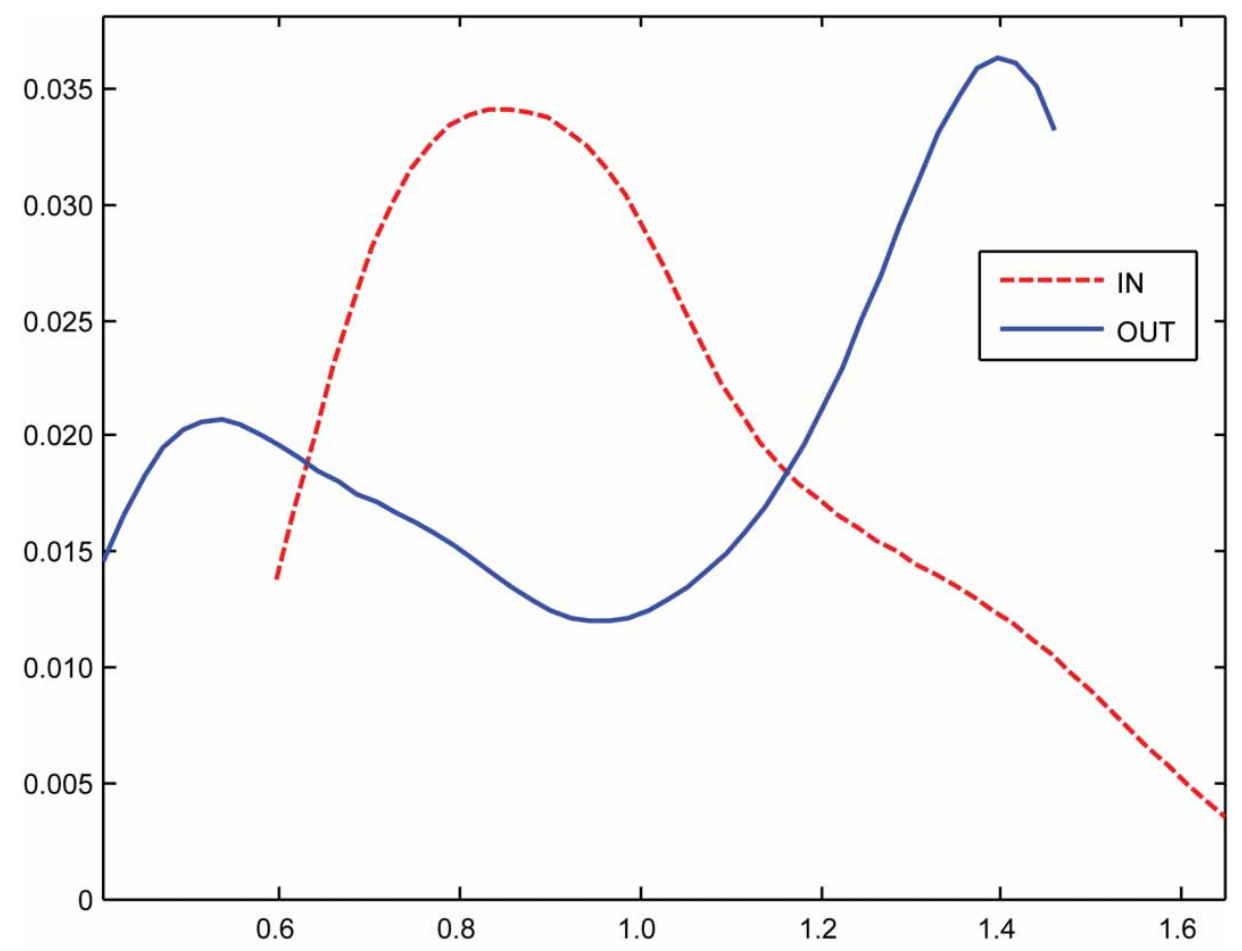

\begin{tabular}{|l|c|c|}
\hline & Standard deviation & Interquartile range \\
\hline IN (peak-to-peak) & 0.2572 & 0.3877 \\
\hline OUT (trough-to-peak) & 0.3380 & 0.6246 \\
\hline
\end{tabular}

Fig. 6. Comparison between distribution dynamics: peak to peak: 1989:Q1-1994:Q4; 1994:Q4-2000:Q1; 2000:Q12007:Q2; and trough to peak: 1991:Q4-1994:Q4; 1995:Q4-2000:Q1; 2003:Q1-2007:Q2

Note: Estimates were obtained using normal-scale bandwidths (SILVERMAN, 1986) and a Gaussian kernel. A local linear estimate of the mean function was employed for the mean bias adjustment (HYNDMAN et al., 1996) 
convergence analysis. In order to do so, the results found in the 'in phase' analysis were compared with those arising from an 'out of phase' one. In particular, the 'out of phase' analysis was defined as the one based on one or more transitions running from opposite turning points, that is, either from peak to trough or from trough to peak. It was assumed that, as previously suggested, disparities followed a pro-cyclical behaviour. Then, when the 'out of phase' transition was derived by removing an expansion (slowdown) from a larger 'in phase' transition, the results were then expected to be biased towards (against) convergence.

\section{Convergence analysis}

The results of the convergence analysis among US states over the period 1989-2007 are reported in Figs 3 and 4. Each figure shows the estimate of the stochastic kernel (both the three-dimensional plot and the contour plot), an estimate of the cross-sectional distribution at the beginning of the considered transitions, and the estimate of the ergodic distribution.

Focusing on a single transition between the peak of 1989:Q1 and the peak of 2007:Q2 (Fig. 3), the estimate of the stochastic kernel shows a weak tendency toward convergence only for the states belonging to the very end of the left tail of the cross-sectional distribution. In contrast, there seems to be a clockwise rotation of the probability mass, suggesting the presence of diverging dynamics, in a neighbourhood of the sample mean. Consistently, compared with the initial, the ergodic distribution indicates a tendency towards divergence due to the emergence of a second mode in correspondence to a value of $20 \%$ in excess of the sample mean. Fundamentally, the same type of conclusions can be drawn also from Fig. 4 where the estimates obtained using three peak-to-peak transitions are reported. $^{7}$ In sum, it appears that over the period stretching across approximately two decades, US states have been characterized by a process of divergence in terms of personal income per capita. ${ }^{8}$

\section{Influence of the period of analysis}

Now that the dynamics characterizing the recent experience of the distribution of personal income per capita across US states have been established, it is possible to move to the second purpose of the study and show if, and how, short-run distribution dynamics along the business cycle affect the results.

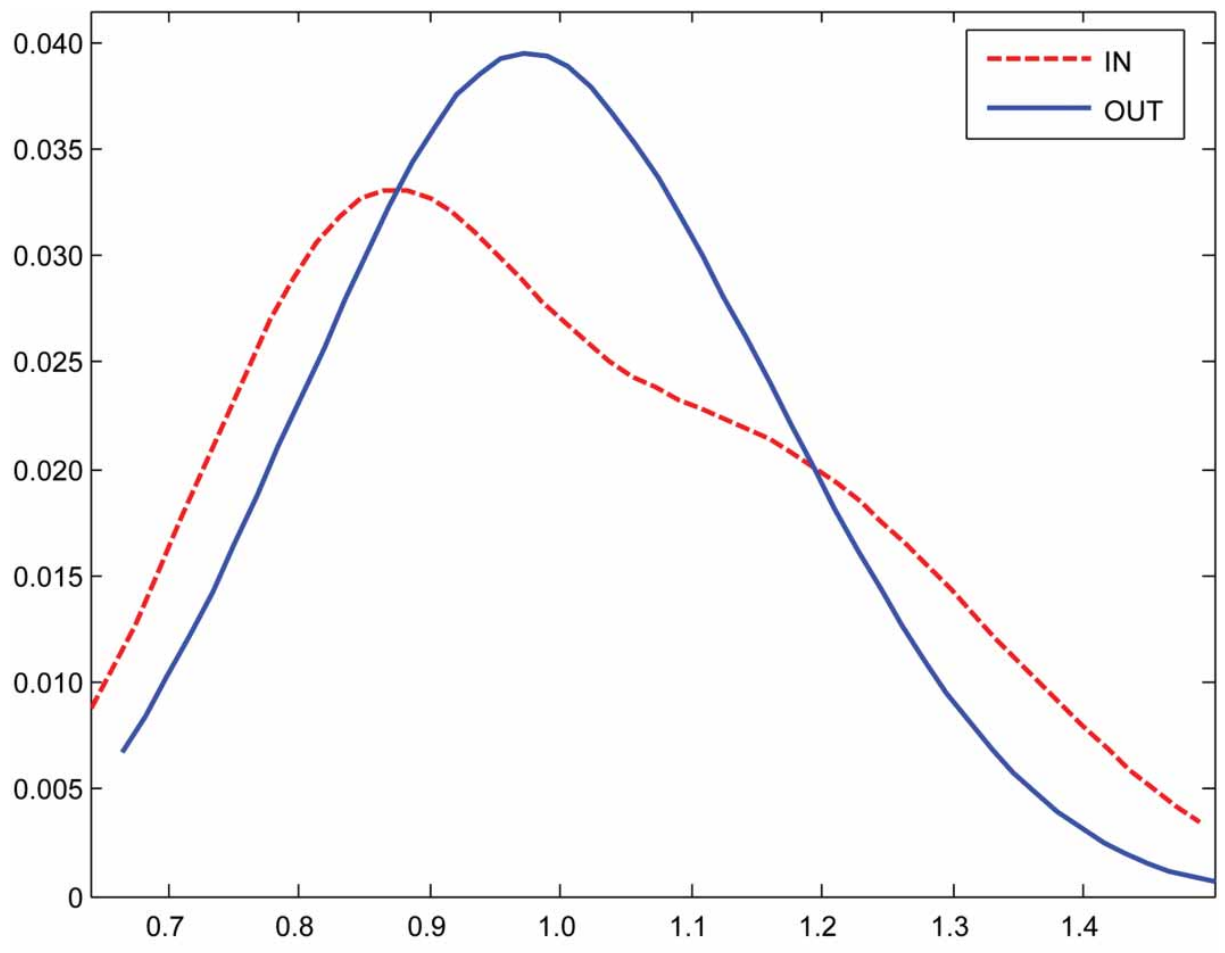

\begin{tabular}{|l|c|c|}
\hline & Standard deviation & Interquartile range \\
\hline IN (peak-to-peak) & 0.2028 & 0.3288 \\
\hline OUT (peak-to-trough) & 0.1650 & 0.2213 \\
\hline
\end{tabular}

Fig. 7. Comparison between distribution dynamics: peak to peak: 1989:Q1-2007:Q2; and peak to trough: 1989:Q1-2003:Q1 Note: Estimates were obtained using normal-scale bandwidths (SILVERMAN, 1986) and a Gaussian kernel. A local linear estimate of the mean function was employed for the mean bias adjustment (HYNDMAN et al., 1996) 
As anticipated, to do so a set of comparisons between two ergodic distributions are carried out: an 'in phase' distribution and an 'out of phase' one. The 'in phase' distribution is estimated on transition periods running between different peaks of the business cycle and effectively corresponds to the ergodic distribution estimates reported in the fourth section. Then, for each peak-to-peak transition characterizing the 'in phase' estimate, two types of 'out of phase' estimates can be considered. The first is obtained by concentrating on the transition between an in-between trough and the final peak, thereby removing the slowdown period running from the initial peak and the intermediate trough; the second type of estimate is instead obtained by considering the transition between the initial peak and the intermediate trough, in which case the expansion period running from the intermediate trough and the final peak has been removed. If distribution dynamics effectively move in a pro-cyclical fashion, the first type of 'out of phase' ergodic estimate is therefore expected to display a more pronounced tendency towards divergence in comparison with the 'in phase' estimate. In contrast, the second type of 'out of phase' ergodic estimate should exhibit a more marked tendency towards convergence.

To draw conclusions, attention can be primarily focused on the visual inspection of differences in the shape of the estimated ergodic distributions. In each of the considered cases, however, the evidence provided by the graph is supported by adding a comparison between dispersion indexes such as the standard deviation and the interquartile range.

The first of these comparisons is reported in Figs 5-8. In particular, Figs 5 and 6 report the results, respectively based on one and three transition periods, when 'out of phase' definition is of the first type and hence excludes slowdown periods. In this case, the introduction of a bias towards divergence is quite evident from the shape of the ergodic distributions: in both figures, the 'out of phase' ergodic distribution estimate is markedly bimodal and characterized by higher values for the dispersion indexes. ${ }^{9}$

Analogously, Figs 7 and 8 provide an account of the consequences of defining the 'out of phase' transition by excluding expansion periods. As expected, the ergodic distribution corresponding to the 'out of phase' transitions is showing substantial convergence if compared

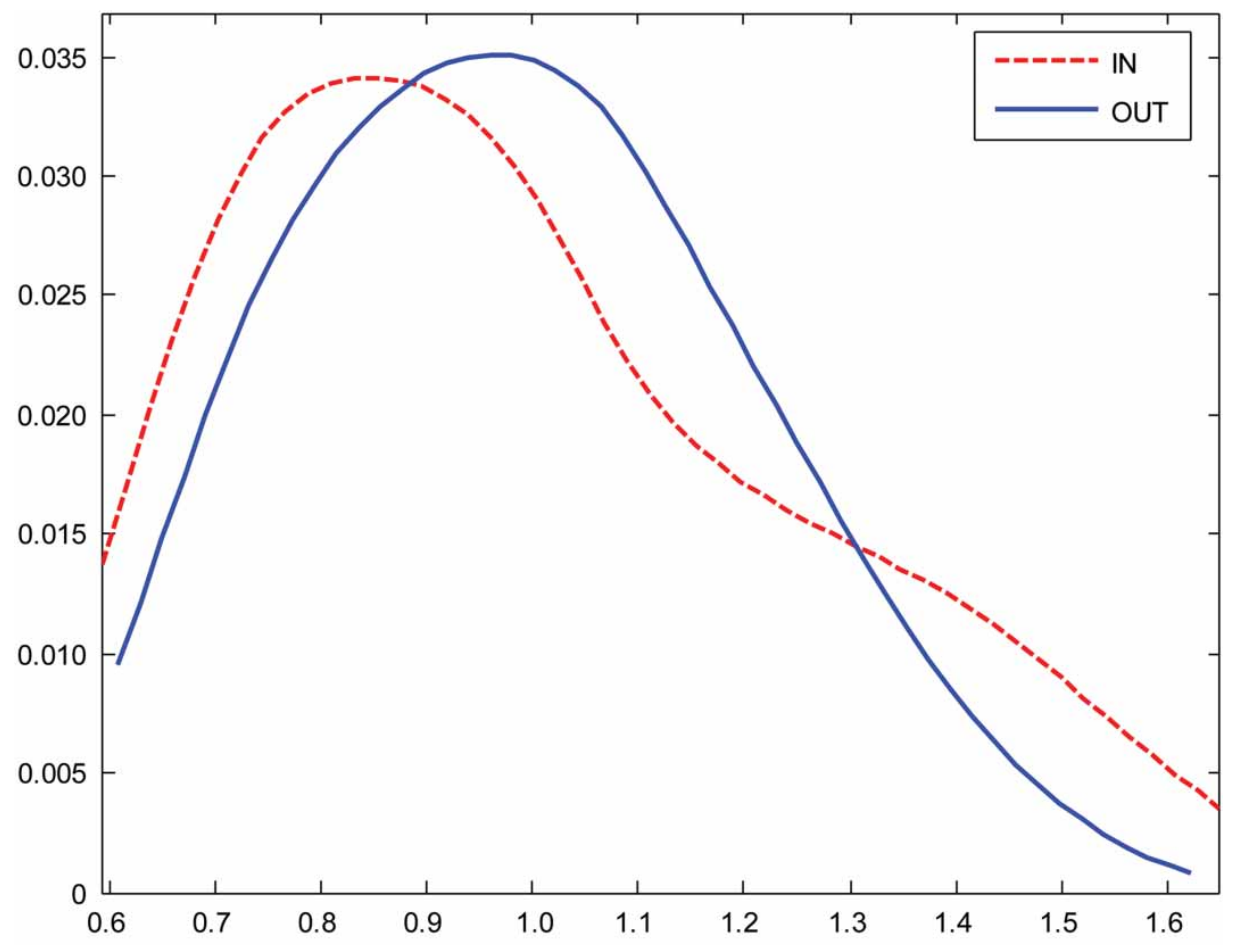

\begin{tabular}{|l|c|c|}
\hline & Standard deviation & Interquartile range \\
\hline IN (peak-to-peak) & 0.2572 & 0.3877 \\
\hline OUT (peak-to-trough) & 0.2133 & 0.3106 \\
\hline
\end{tabular}

Fig. 8. Comparison between distribution dynamics: peak to peak: 1989:Q1-1994:Q4; 1994:Q4-2000:Q1; 2000:Q12007:Q2; and peak to trough: 1989:Q1-1991:Q4; 1994:Q4-1995:Q4; 2000:Q1-2003:Q1

Note: Estimates were obtained using normal-scale bandwidths (SILVERMAN, 1986) and a Gaussian kernel. A local linear estimate of the mean function was employed for the mean bias adjustment (HYNDMAN et al., 1996) 
with the 'in phase' distribution. ${ }^{10}$ In addition, this implication is clearly confirmed by the reported values of the standard deviation and interquartile range. Finally, as reported in the figures in Appendix B, the same type of conclusions can be drawn when the analysis is replicated using the turning points based on Baxter-Kingfiltered data or as defined by the NBER.

A final aspect that is worth considering relates to the common practice of dividing the period of analysis into a number of sub-periods of the same length. As a result, the detected dynamics still characterize the entire period, but with reference to transitions of length equal to the sub-periods' length. The main reason behind this operation is that it allows one to make use of a richer set of information and thus improve the quality of the estimates. Given the results reported so far, however, it is plausible that this commonly adopted practice is not harmless since the extension of the sub-period is unlikely to coincide with the length of the cycle phases.

The period of analysis selected in this study stretches between the first quarter of 1989 and the second quarter of 2007. If this is divided into three transitions of approximately the same length, the resulting subperiods overlap almost completely with those based on the phases of the US cycle. In particular, a mechanical split of the time span leads to transition of twenty-four or twenty-five quarters, which means that the first sub-period would end in 1994:Q4 and the second in 2001:Q1. In other words, by pure chance the analysis based on a mechanical split of the period is likely to coincide with the one reported in Fig. 4. Indeed, this is clearly the message conveyed by the comparison represented in Fig. 9.

Therefore, in order to show that the problem just emphasized is not just a theoretical possibility, the period is sub-divided in a somewhat different way but still retaining the ability to allow for the cyclical behaviour of the cross-sectional disparities. The 1994:Q4 peak is therefore ignored and two sub-periods separated by the 2000:Q1 peak are identified. In such a way, the first sub-period runs between 1989:Q1 and 2000:Q1 (approximately eleven years), and the second between 2000:Q1 and 2007:Q2 (approximately seven years). The analysis carried out over the transition periods thus identified is compared with an analysis conducted using two mechanically determined sub-periods of identical length (hence separated by 1998:Q1).

As clearly shown in Fig. 10, in this case the results arising from the mechanical split are affected by a

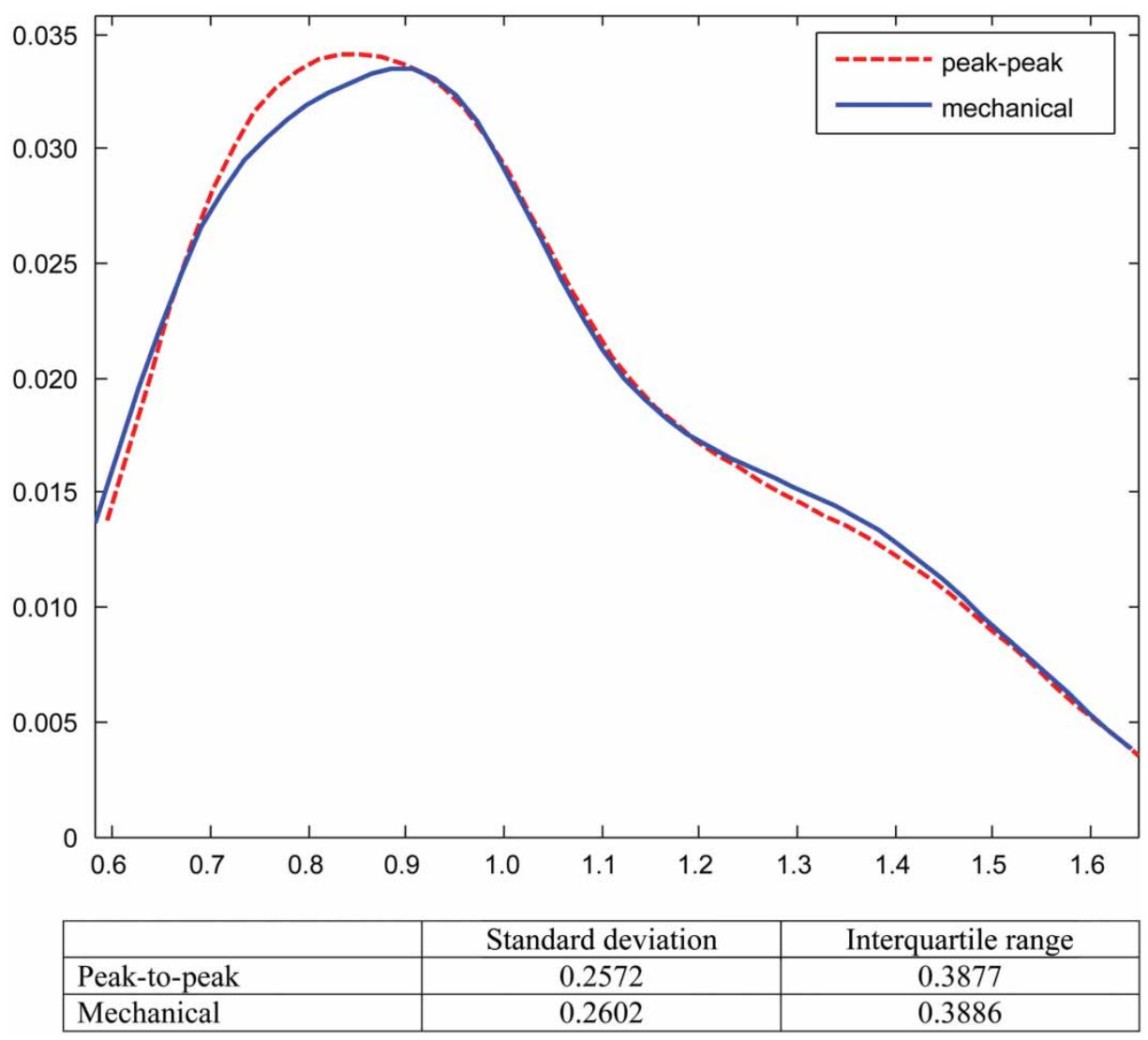

Fig. 9. Comparison between distribution dynamics: peak to peak: 1989:Q1-1994:Q4; 1994:Q4-2000:Q1; 2000:Q12007:Q2; and mechanical: 1989:Q1-1995:Q1; 1995:Q1-2001:Q2; 2001:Q2-2007:Q2

Note: Estimates were obtained using normal-scale bandwidths (SILVERMAN, 1986) and a Gaussian kernel. A local linear estimate of the mean function was employed for the mean bias adjustment (HYNDMAN et al., 1996) 


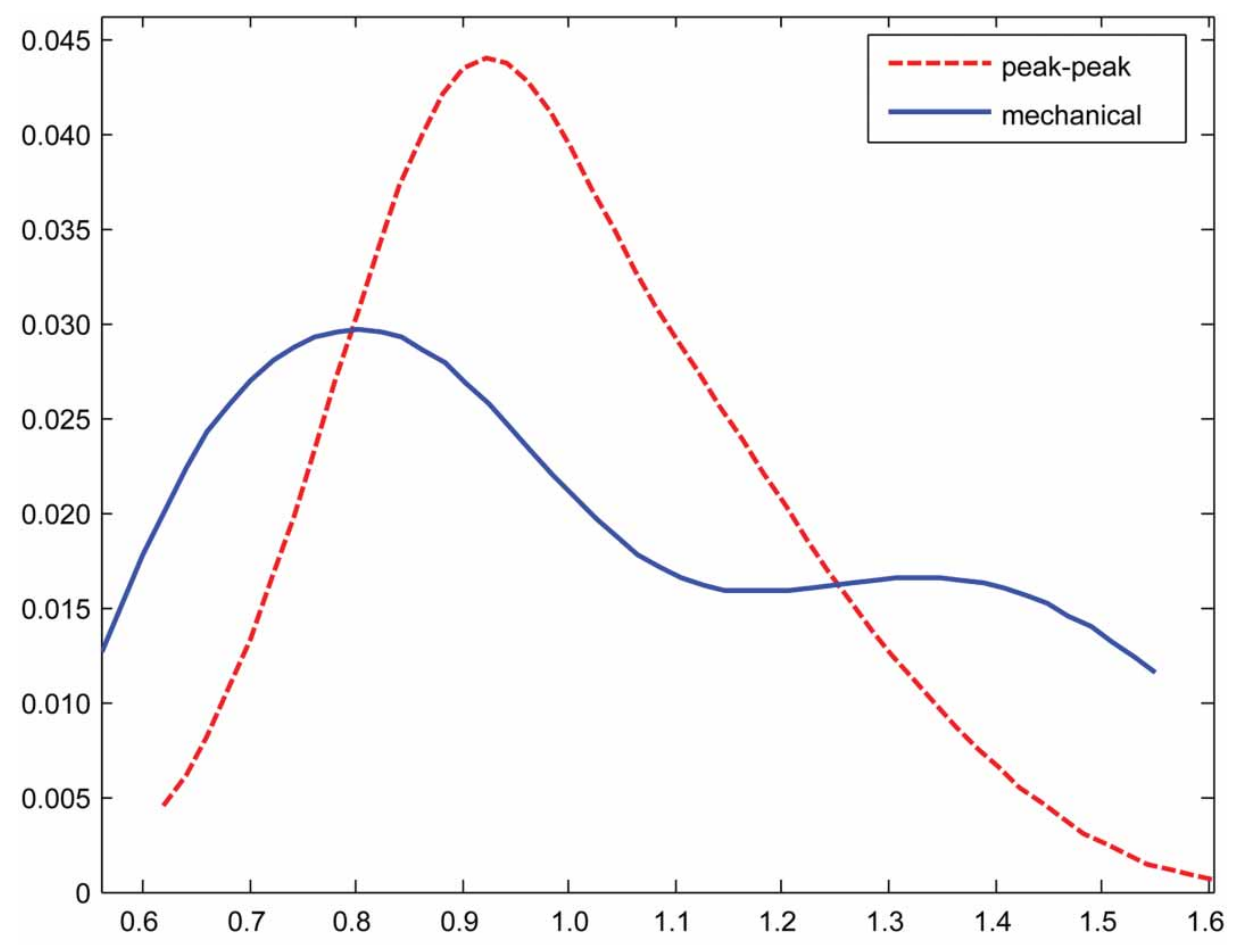

\begin{tabular}{|l|c|c|}
\hline & Standard deviation & Interquartile range \\
\hline Peak-to-peak & 0.1902 & 0.2612 \\
\hline Mechanical & 0.2753 & 0.4649 \\
\hline
\end{tabular}

Fig. 10. Comparison between distribution dynamics: peak to peak: 1989:Q1-2000:Q1; 2000:Q1-2007:Q2; and mechanical: 1989:Q1-1998:Q1; 1998:Q1-2007:Q2

Note: Estimates were obtained using normal-scale bandwidths (SILVERMAN, 1986) and a Gaussian kernel. A local linear estimate of the mean function was employed for the mean bias adjustment (HYNDMAN et al., 1996)

severe distortion: the corresponding ergodic distribution is substantially different from the one obtained through a cycle-based split and markedly bimodal.

Two final remarks are in order here. First, it must be emphasized that despite the fact that the overall period is the same and defined according to the aggregate cycle, profoundly different results emerge. This is simply because the sub-periods have been defined differently. Second, even knowing whether disparities were proor anti-cyclical, it would still be impossible to predict the direction of the distortion introduced via the mechanical splitting. Intuitively, the overall level of distortion is a somewhat net effect of the distortions present in each sub-period whose size and direction depend on where mechanically defined boundaries are located with respect to the cycle turning points.

\section{CONCLUSIONS}

This paper assessed the importance of the choice of the period of analysis in relation to the cyclical behaviour of cross-sectional income disparities while investigating convergence dynamics.

First, the business cycle for the US economy was identified using the Hodrick-Prescott filter and then the turning points of the cycle were detected with the Bry-Boschan algorithm. The overall period of analysis that was consequently selected starts with the peak identified in the first quarter of 1989 and ends with the peak detected in the second quarter of 2007. Over this period, it appears that per capita personal income disparities across forty-eight coterminous US states follow a cyclical pattern. In particular, the visual inspection of the evolution of the coefficient of variation in relation to the timing of the US business cycle phases suggests that disparities move in a procyclical fashion.

Second, assuming that the just-reported cyclical behaviour might actually affect dynamics, convergence across the states of the United States is studied over periods that allow for the cyclical movement of the aggregate economy. Through a comparison between the initial and the ergodic distribution, a tendency towards divergence due to the emergence of a second mode in correspondence with a value of $20 \%$ in excess of the sample mean was identified. This finding was then confirmed using three peak-to-peak transitions. It was then demonstrated that the definition of the period of analysis without allowing for the cyclical movements of the aggregate economy might indeed 
seriously affect the dynamics and lead to misrepresented results.

Finally, it was also shown that the commonly adopted practice of dividing the period of analysis into a number of sub-periods of the same length might also bear important consequences. A mechanical subdivision of a correctly identified overall period of analysis might indeed introduce a distortion of a similar size to the one detected when the period of analysis is incorrectly identified.

To sum up, an incorrect choice of a period of analysis (that is, a period that does not contain entirely both phases of the cycle), as well as a mechanical subdivision of a correctly identified period into transitions of the same length, is likely to produce misleading results. It is only when the analysed time period includes exactly one (or more) entire business cycles that the researcher may be able to recover the true underlying dynamics of cross-sectional income disparities.

These considerations are not only interesting per se, but they also have far-reaching consequences for regional policy. From a policy-maker viewpoint it is indeed important to recognize whether regional disparities move along the business cycle and hence to discriminate between a short-run component of the disparities, possibly bound to vanish, and the long-run one. While the type of intervention required by an increase in disparities due to the short-run component might possibly be limited temporarily to sustaining income in less favoured regions (for instance, through direct and indirect income transfers), in the case of a long-run increase in disparities quite different structural interventions might be called for (for instance, policies aimed at fostering infrastructure upgrading in strategic sectors, sustaining the development of human capital, and improving the environment for both innovation and firm creation). In addition, the sign of the association between regional disparities and cyclical swings also matters. In particular, it is important to emphasize that in the case of a counter-cyclical behaviour, disparities tend to enlarge during slowdowns, that is, during periods in which it is reasonable to expect that fewer resources could be devoted to short-term policies aimed at tackling them.

Finally, it is important to keep a clear distinction between short- and long-run implications of the results reported here. It has been shown that during the 19892007 period, regional disparities display a pro-cyclical behaviour and that the underlying long-run tendency is towards divergence. However, it must be stressed that the second result cannot be inferred from the first. More explicitly, pro-cyclical disparities do not necessarily imply that disparities increase in the long-run when the aggregate economy is growing, nor that policies aimed at fostering growth of the aggregate economy in the long-run necessarily lead to a steady increase in regional disparities. Indeed, the determinants of short- and longrun dynamics in regional disparities could differ significantly so that the increase in regional disparities detected during an expansion phase might be more than compensated for during the slowdown, thus leading to a net reduction over the entire cycle.

Acknowledgements - The authors would like to thank two anonymous referees and the Editors for their helpful comments and useful suggestions. Any errors are the responsibility of the authors alone. 


\section{APPENDIX A: CONVERGENCE DYNAMICS USING ALTERNATIVE CYCLE DATINGS}

\section{Stochastic kernel}

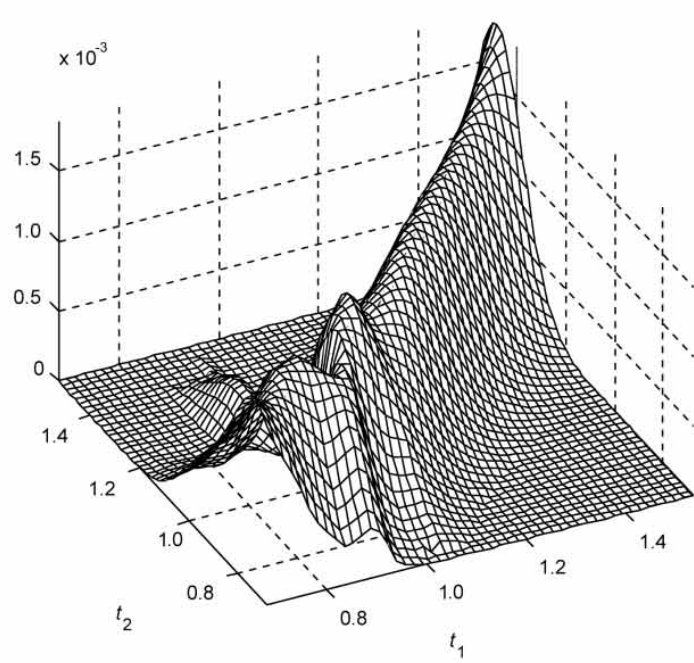

Initial $\left(t_{1}\right)$

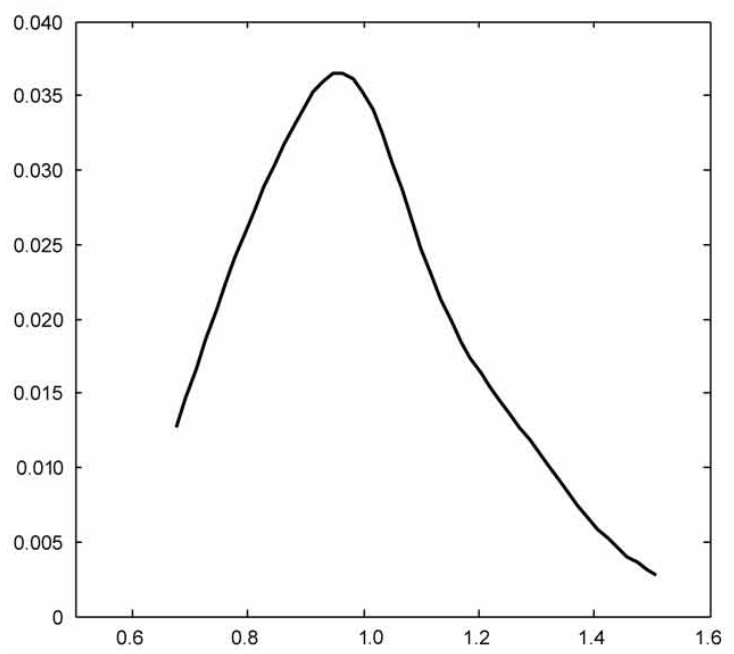

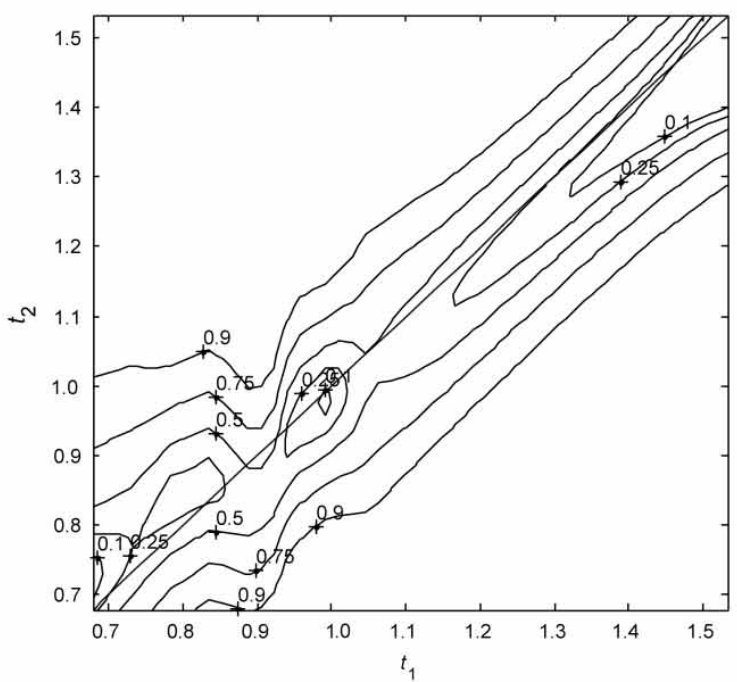

Ergodic

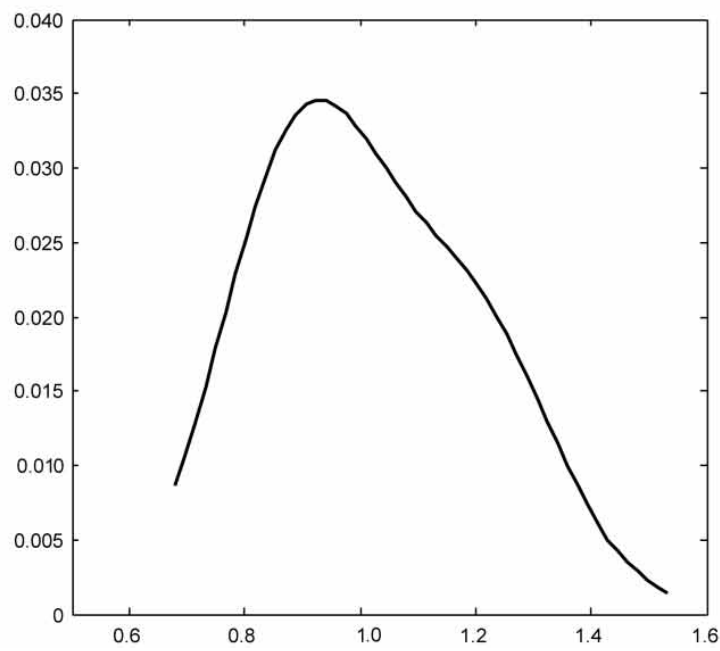

Fig. A1. Convergence dynamics (dating based on Baxter-King-filtered data): peak to peak: 1988:Q4-2007:Q3 Note: Estimates were obtained using normal-scale bandwidths (SILVERMAN, 1986) and a Gaussian kernel. A local linear estimate of the mean function was employed for the mean bias adjustment (HYNDMAN et al., 1996). In the plots, $t_{1}$ refers to the initial moment(s) of the transition period(s) 


\section{Stochastic kernel}

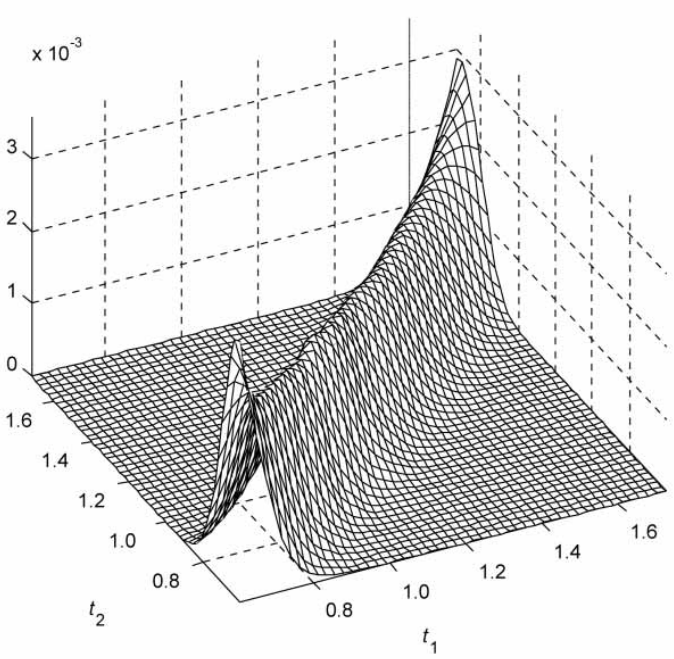

Initial $\left(t_{1}\right)$
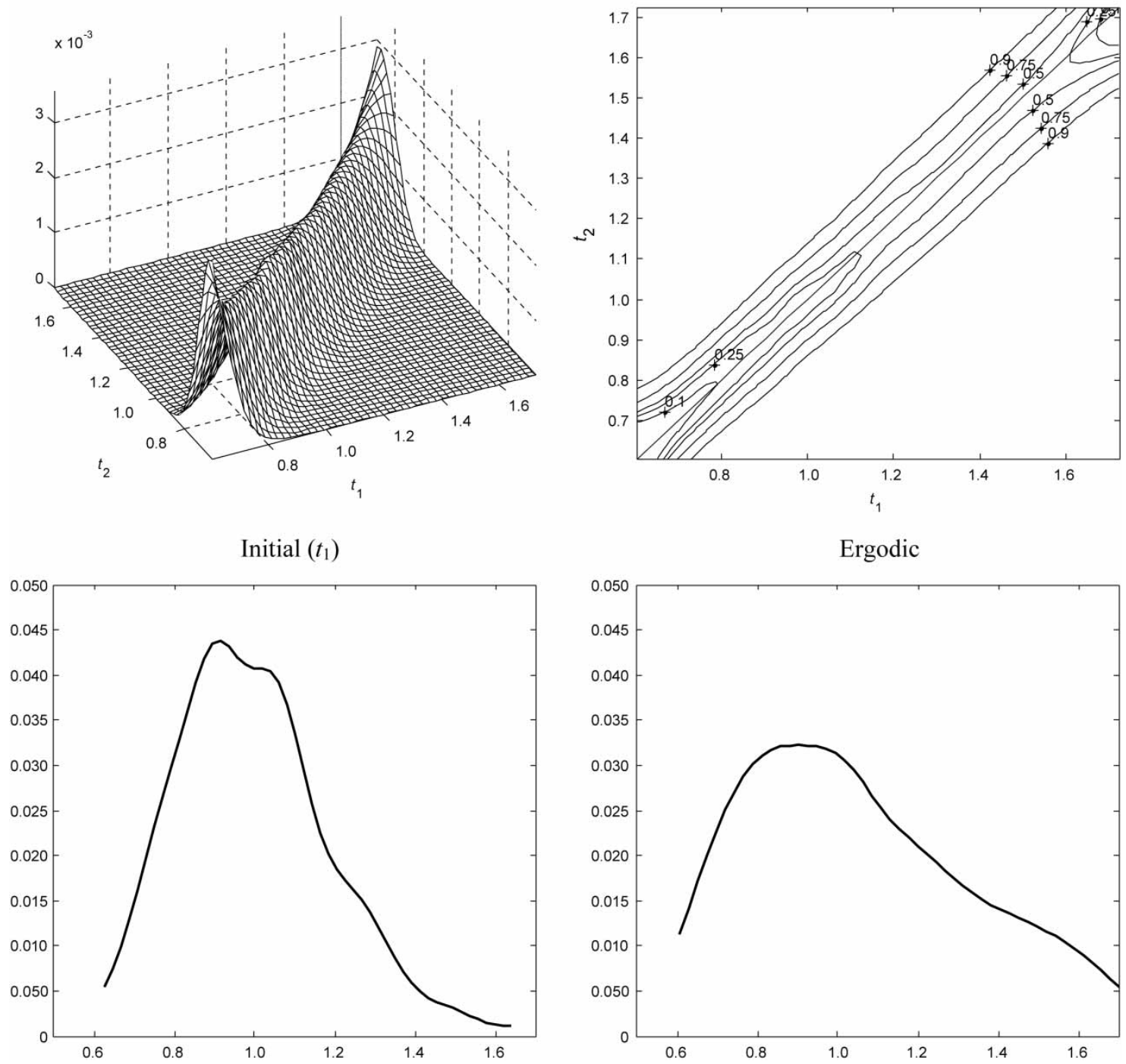

Ergodic

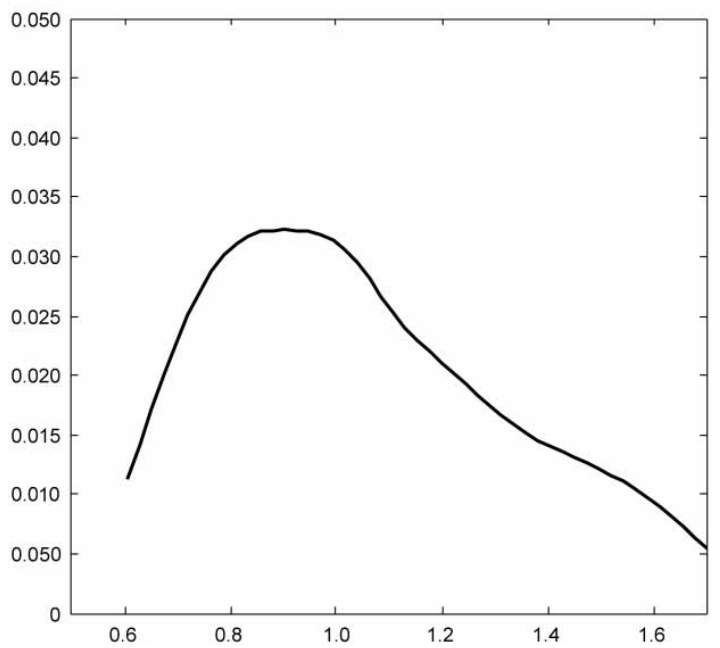

Fig. A2. Convergence dynamics (dating based on Baxter-King-filtered data): peak to peak: 1988:Q4-1992:Q3; 1992:Q31994:Q3; 1994:Q3-1998:Q3; 1998:Q3-2000:Q3; 2000:Q3-2004:Q3; 2004:Q3-2007:Q3

Note: Estimates were obtained using normal-scale bandwidths (SILVERMAN, 1986) and a Gaussian kernel. A local linear estimate of the mean function was employed for the mean bias adjustment (HyNDMAN et al., 1996). In the plots, $t_{1}$ refers to the initial moment(s) of the transition period(s) 


\section{Stochastic kernel}

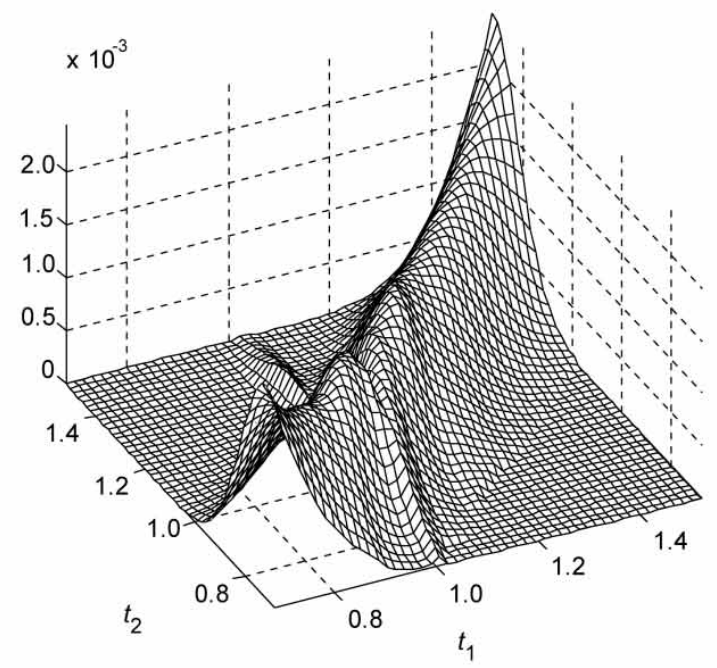

Initial

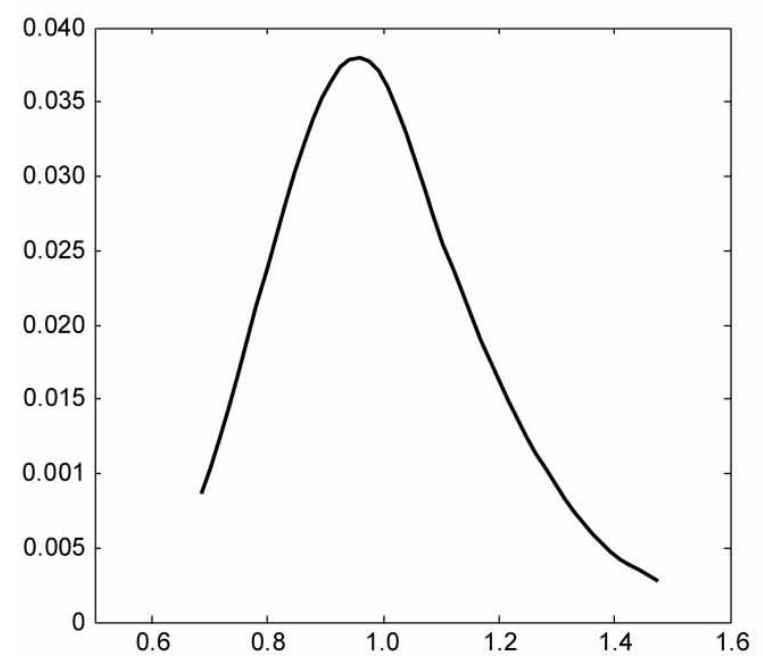

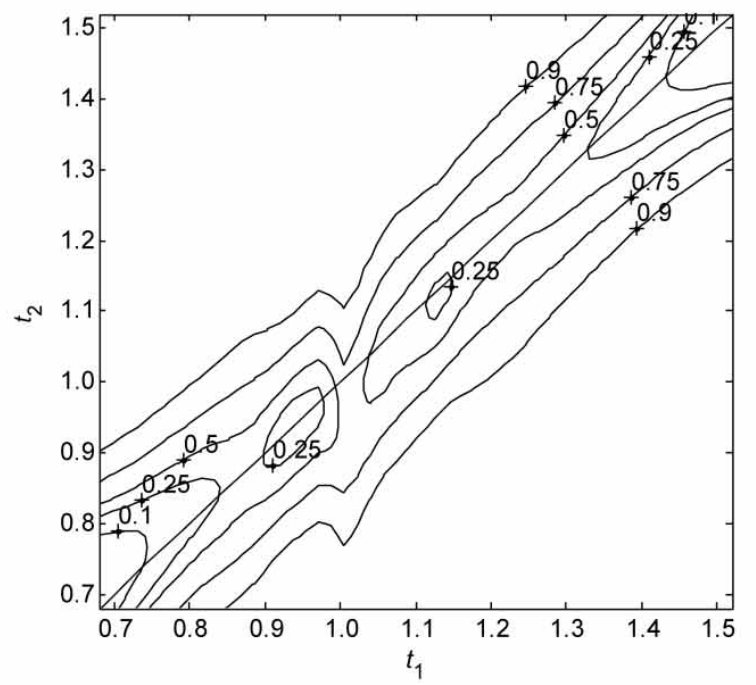

Ergodic

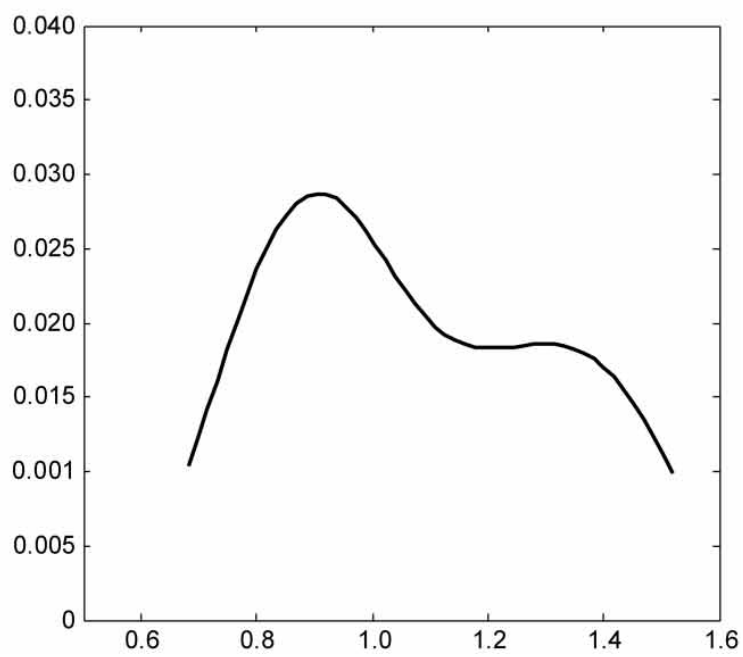

Fig. A3. Convergence dynamics (National Bureau of Economic Research (NBER) dating): peak to peak: 1990:Q3-2007:Q4 Note: Estimates were obtained using normal-scale bandwidths (SILVERMAN, 1986) and a Gaussian kernel. A local linear estimate of the mean function was employed for the mean bias adjustment (HYNDMAN et al.1996). In the plots, $t_{1}$ refers to the initial moment(s) of the transition period(s) 


\section{APPENDIX B: COMPARISON BETWEEN DISTRIBUTION DYNAMICS USING ALTERNATIVE} CYCLE DATINGS

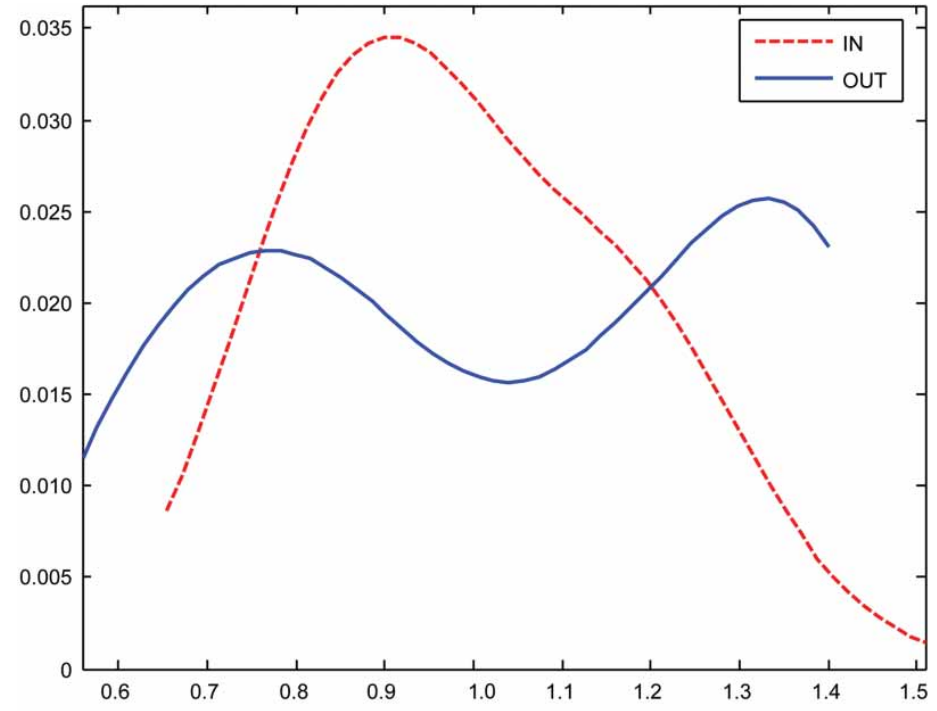

\begin{tabular}{|l|c|c|}
\hline & Standard deviation & Interquartile range \\
\hline IN (peak-to-peak) & 0.1882 & 0.2964 \\
\hline OUT (trough-to-peak) & 0.2517 & 0.4468 \\
\hline
\end{tabular}

Fig. B1. Comparison between distribution dynamics (dating based on Baxter-King-filtered data): peak to peak: 1988:Q42007:Q3; and trough to peak: 1991:Q3-2007:Q3

Note: Estimates were obtained using normal-scale bandwidths (SILVERMAN, 1986) and a Gaussian kernel. A local linear estimate of the mean function was employed for the mean bias adjustment (HYNDMAN et al., 1996)

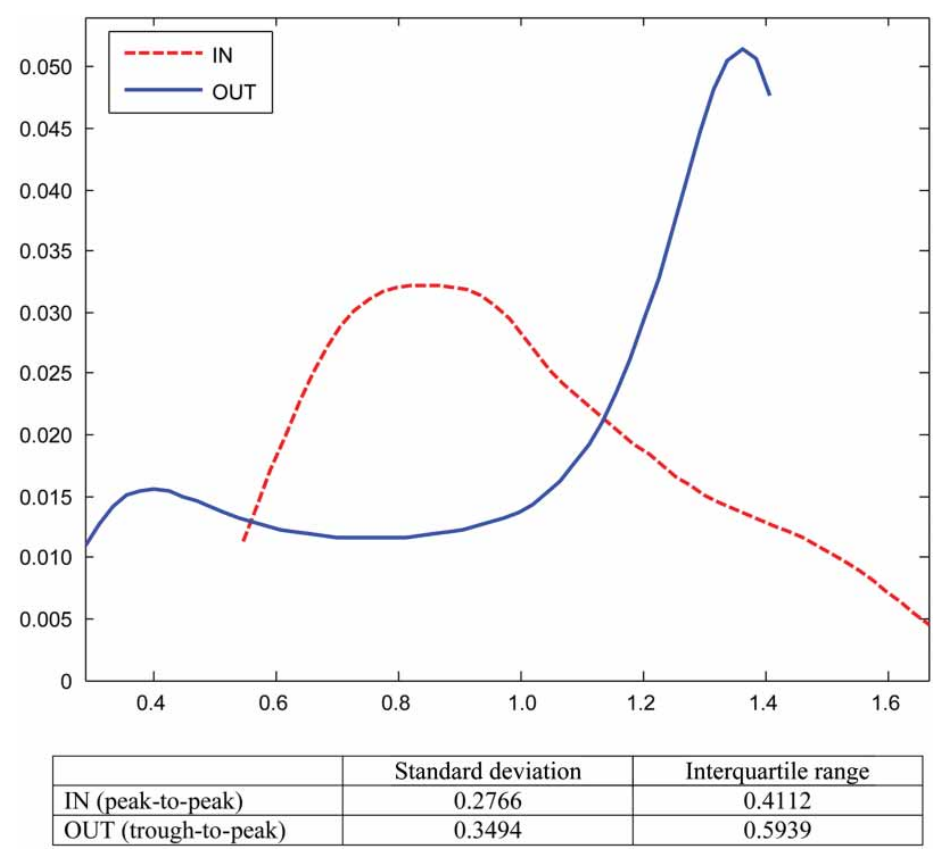

Fig. B2. Comparison between distribution dynamics (dating based on Baxter-King-filtered data): peak to peak: 1988:Q41992:Q3; 1992:Q3-1994:Q3; 1994:Q3-1998:Q3; 1998:Q3-2000:Q3; 2000:Q3-2004:Q3; 2004:Q3-2007:Q3; and trough to peak: 1991:Q3-1992:Q3; 1993:Q3-1994:Q3; 1997:Q2-1998:Q3; 1999:Q2-2000:Q3; 2002:Q12004:Q3; 2005:Q2-2007:Q3

Note: Estimates were obtained using normal-scale bandwidths (SILVERMAN, 1986) and a Gaussian kernel. A local linear estimate of the mean function was employed for the mean bias adjustment (HYNDMAN et al., 1996) 


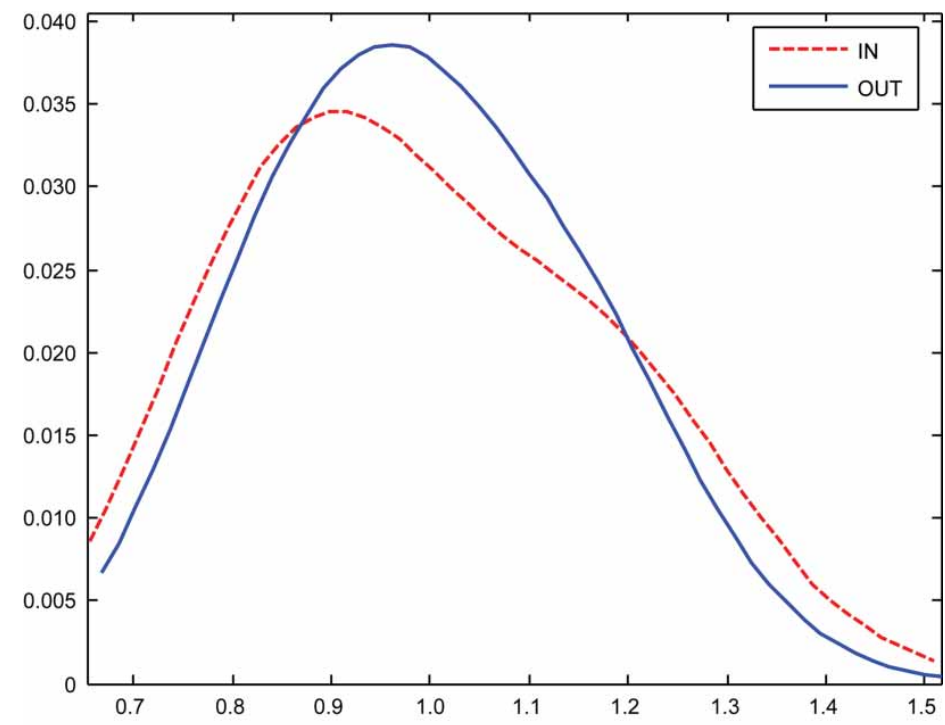

\begin{tabular}{|l|c|c|}
\hline & Standard deviation & Interquartile range \\
\hline IN (peak-to-peak) & 0.1882 & 0.2964 \\
\hline OUT (peak-to-trough) & 0.1661 & 0.2426 \\
\hline
\end{tabular}

Fig. B3. Comparison between distribution dynamics (dating based on Baxter-King-filtered data): peak to peak: 1988:Q42007:Q3; and peak to trough: 1988:Q4-2005:Q2

Note: Estimates were obtained using normal-scale bandwidths (SILVERMAN, 1986) and a Gaussian kernel. A local linear estimate of the mean function was employed for the mean bias adjustment (HyNDMAN et al., 1996)

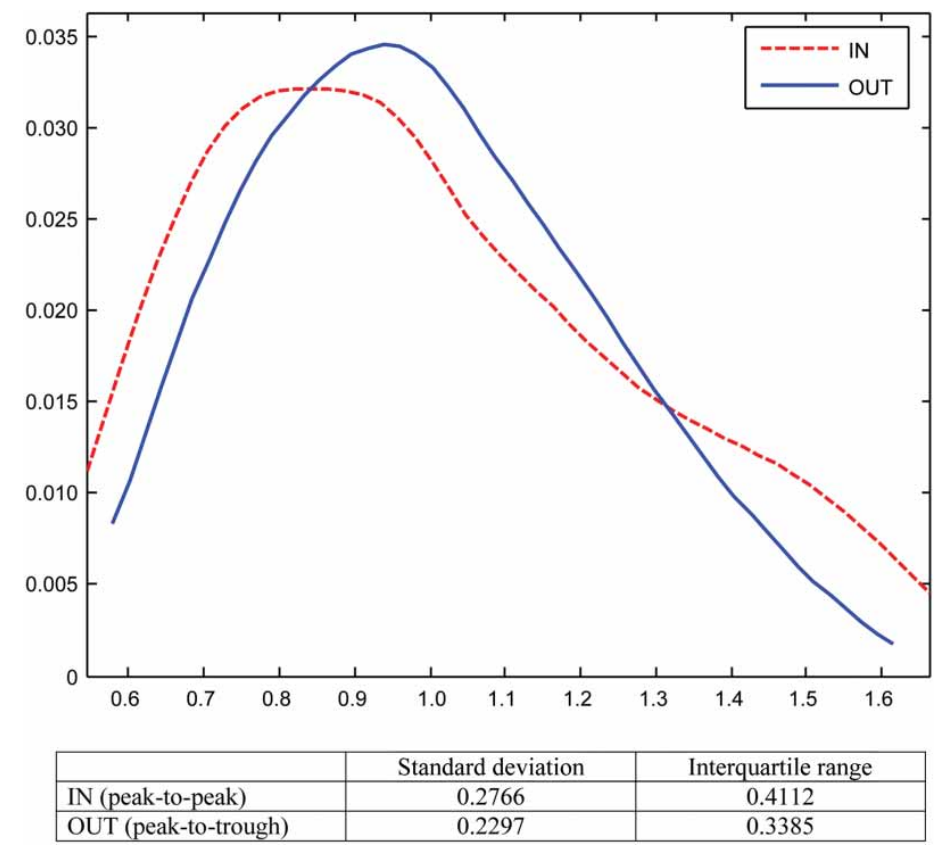

Fig. B4. Comparison between distribution dynamics (dating based on Baxter-King-filtered data): peak to peak: 1988:Q41992:Q3; 1992:Q3-1994:Q3; 1994:Q3-1998:Q3; 1998:Q3-2000:Q3; 2000:Q3-2004:Q3; 2004:Q3-2007:Q3; and peak to trough: 1988:Q4-1991:Q3; 1992:Q3-1993:Q3; 1994:Q3-1997:Q2; 1998:Q3-1999:Q2; 2000:Q32002:Q1; 2004:Q3-2005:Q2

Note: Estimates were obtained using normal-scale bandwidths (SILVERMAN, 1986) and a Gaussian kernel. A local linear estimate of the mean function was employed for the mean bias adjustment (HYNDMAN et al., 1996) 


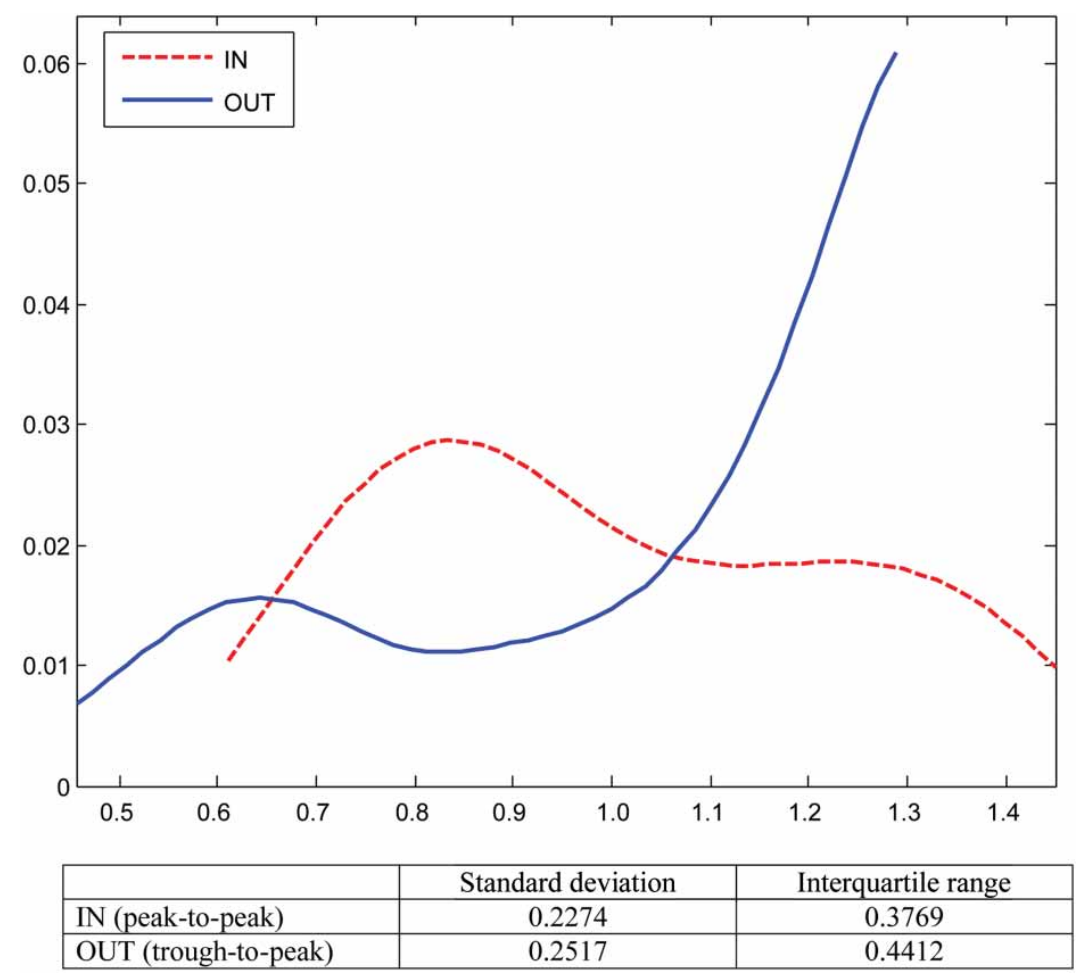

Fig. B5. Comparison between distribution dynamics (National Bureau of Economic Research (NBER) dating): peak to peak: 1990:Q3-2007:Q4; and trough to peak: 1991:Q1-2007:Q4

Note: Estimates were obtained using normal-scale bandwidths (SILVERMAN, 1986) and a Gaussian kernel. A local linear estimate of the mean function was employed for the mean bias adjustment (HYNDMAN et al., 1996)

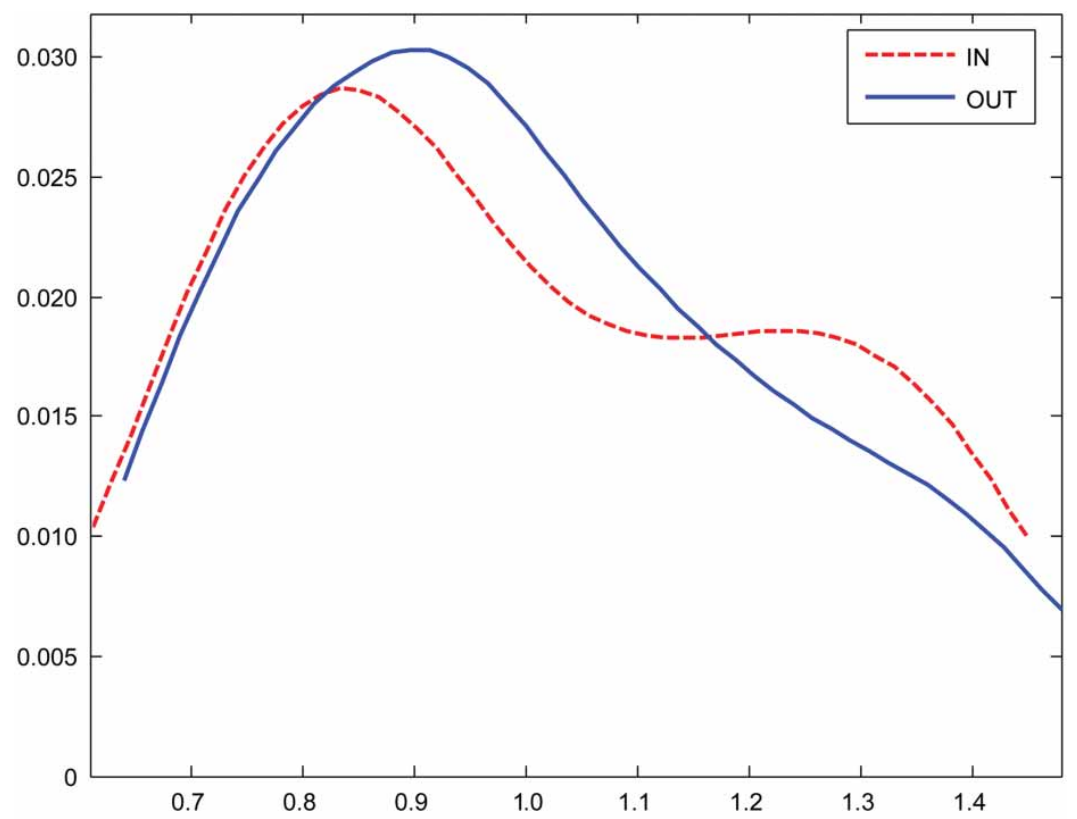

\begin{tabular}{|l|c|c|}
\hline & Standard deviation & Interquartile range \\
\hline IN (peak-to-peak) & 0.2274 & 0.3769 \\
\hline OUT (peak-to-trough) & 0.2145 & 0.3257 \\
\hline
\end{tabular}

Fig. B6. Comparison between distribution dynamics (National Bureau of Economic Research (NBER) dating): peak to peak: 1990:Q3-2007:Q4; and peak to trough: 1990:Q3-2001:Q4

Note: Estimates were obtained using normal-scale bandwidths (SILVERMAN, 1986) and a Gaussian kernel. A local linear estimate of the mean function was employed for the mean bias adjustment (HYNDMAN et al., 1996) 


\section{NOTES}

1. Denoting income at time $t$ with $y t$, the HP filter minimizes in $\tau t$ the following expression:

$\min \sum_{t=1}^{T}\left(y_{t}-\tau_{t}\right)^{2}+\lambda \sum_{t=2}^{T-1}\left[\left(\tau_{t+1}-\tau_{t}\right)-\left(\tau_{t}-\tau_{t-1}\right)\right]^{2}$

where $\lambda$ is a penalty parameter which captures the smoothness of the trend $\tau t$. Specifically, the first term represents the deviations of income from the trend, while the second term is the product of $\lambda$ and the sum of the squares of the second differences of the trend component which penalizes variations in the growth rate of the trend. Penalty increases with $\lambda$, producing smoother estimates, and as suggested by the authors in the case of quarterly data, $\lambda=1600$ was set.

2. The Bry-Boschan algorithm is designed to detect, initially, the set of local minima and maxima in the income series and it then imposes several restrictions on the duration of the phases and cycles in order to ensure their persistence. In the present analysis the minimum phase and cycle length were set as two and five quarters, respectively.

3. The paper does not primarily concentrate on NBER turning points because the NBER detects the turning points referring directly to classical cycles while the present paper instead uses deviation cycles; besides, the NBER uses many aggregate variables when detecting the turning points while this paper only uses personal income data.

4. A further possibly critical issue concerns the effects of spatial dependence on the kernel density estimates. While in the parametric literature, and in particular in the literature on convergence within the regression approach, there is a full awareness that neglecting spatial dependence may lead to biased and inefficient estimates, this issue has been almost ignored so far within the non-parametric literature. Therefore, for example, REY and JANIKAS (2005) in their discussion of the properties of kernel density estimators noted that 'the properties of these estimators in the presence of spatial dependence are unknown' (p. 165).

5. The kernel $K(\bullet)$ is assumed to be a real valued, integrable, non-negative, even function.

6. Appendix $\mathrm{B}$ also reports results obtained using the turning points dated on Baxter-King-filtered data (BAXTER and KING, 1999) and the official turning points provided by the NBER. As explained above, it must be emphasized that NBER turning points are not fully compatible with the present framework since NBER dating is based on a wide set of indicators (rather than just personal income) and refers to classical cycles (rather than deviation cycles). For this reason, when using NBER turning points, only estimates over a single transition period were carried out.

7. The same results were also obtained using the turning points based on Baxter-King-filtered data, either considering just one peak-to-peak transition (Fig. A1) or all possible ones (Fig. A2), and using official NBER turning points (Fig. A3).

8. For the sake of curiosity, the speed of absolute convergence estimated directly via non-linear least squares (Gauss-Newton method) turned out to be 0.0082 (with $p=0.03$ ), a rather low, and not particularly significant rate of convergence.

9. Coherently with theoretical expectations, the speed of absolute convergence estimated over this 'out of phase' period was 0.0002 , which was not significant from a statistical point of view.

10. Also in this case, the difference in the estimated speed of absolute convergence with respect to the 'in phase' analysis was in line with theoretical expectations as it turned out to be equal to 0.0115 (with $p<0.01$ ).

\section{REFERENCES}

Abreu M., De Groot H. L. F. and Florax R. J. G. M. (2005) Space and growth: a survey of empirical evidence and methods, Région and Développement 21, 13-44.

Airov J. (1963) The construction of interregional business cycle models, Journal of Regional Science 5, 1-20.

Azzoni C. R. (2001) Economic growth and regional income inequality in Brazil, Annals of Regional Science 35, $133-152$.

Barro R. J. and Sala-I-Martin X. (1991) Convergence across states and regions, Brooking Papers on Economic Activity no. 1, 107-182.

Barro R. J. and Sala-I-Martin X. (1995) Economic Growth. McGraw-Hill, New York, NY.

Baumol W. J. (1986) Productivity growth, convergence, and welfare: what the long-run data show, American Economic Review 76, 1072-1085.

Baxter M. and King R. G. (1999) Measuring business cycles: approximate bandpass filters, Review of Economics and Statistics 81, $575-593$.

Berry B. (1988) Migration reversals in perspective: the long wave evidence, International Regional Science Review 11, $245-251$.

Bouvet F. (2010) EMU and the dynamics of regional per capita income inequality in Europe, Journal of Economic Inequality 8, 323-344.

Bry G. and Boschan C. (1971) Cyclical Analysis of Time Series: Selected Procedures and Computer Programs. NBER Technical Paper Number 20. National Bureau of Economic Research (NBER), Cambridge, MA.

Bulli S. (2001) Distribution dynamics and cross-country convergence: a new approach, Scottish Journal of Political Economy 48, 226-243.

Chatterji M. and Dewhurst J. H. L. (1996) Convergence clubs and relative economic performance in Great Britain: 1977-1991, Regional Studies 30, 31-39.

Christiano L. and Fitzgerald J. (2003) The band pass filter, International Economic Review 44, 435-465.

Cowell F. A. (2008) Inequality: measurement, in Durlauf S. N. and Blume L. E. (Eds) The New Palgrave Dictionary of Economics, 2nd Edn. Palgrave Macmillan, Basingstoke. The New Palgrave Dictionary of Economics Online DOI:10.1057/9780230226203.0789.

Dewhurst J. H. L. (1998) Convergence and divergence in regional household incomes per head in the United Kingdom, 1984-93, Applied Economics 30, 31-35. 
Dicecio R. and Gascon C. (2010) Income convergence in the United States: a tale of migration and urbanization, Annals of Regional Science 45, 365-377.

Duran E. H. (Forthcoming 2014) Short run dynamics of income disparities and regional cycle synchronization in the U.S, Growth and Change.

Durlauf S. N., Johnson P. A. and Temple J. R. W. (2005) Growth econometrics, in Aghion P. and Durlauf S. N. (Eds) Handbook of Economic Growth, pp. 555-677. Elsevier, Amsterdam.

Durlauf S. N. and Quah D. T. (1999) The new empirics of economic growth, in TaYlor J. and Woodford M. (Eds) Handbook of Macroeconomics, pp. 235-310. Elsevier, Amsterdam.

Firebaugh G. (2003) The New Geography of Global Income Inequality. Harvard University Press, Cambridge, MA.

Hammond G. W. and Thompson E. (2002) Mobility and modality trends in US state personal income, Regional Studies 36, 375-387.

Harding D. and Pagan A. (2003) A comparison of two business cycle dating methods, Journal of Economic Dynamics and Control 27, 1681-1690.

Hodrick R. and Prescott E. C. (1997) Postwar U.S. business cycles: an empirical investigation, Journal of Money, Credit and Banking 29, 1-16.

Hyndman R. J., Bashtannyk D. M. and Grunwald G. K. (1996) Estimating and visualizing conditional densities, Journal of Computational and Graphical Statistics 5, 315-336.

IsLam N. (2003) What have we learnt from the convergence debate?, Journal of Economic Surveys 17, 309-362.

Johnson P. A. (2000) A nonparametric analysis of income convergence across the US states, Economics Letters 69, $219-223$.

Kangasharju A. and Pekkala S. (2004) Increasing regional disparities in the 1990s: the Finnish experience, Regional Studies 38, $255-267$.

Labonte M. (2006) Why Has Household Income Fallen in the Current Expansion While GDP Has Risen? CRS Report for Congress Number RL33519. Congressional Research Service (CRS), Washington, DC.

LoAder C. (1999) Local Regression and Likelihood. Springer, New York, NY.

MAgrini S. (1999) The evolution of income disparities among the regions of the European Union, Regional Science and Urban Economics 29, 257-281.

Magrini S. (2004) Regional (di)convergence, in Henderson J. V. and Thisse J.-F. (Eds) Handbook of Regional and Urban Economics, pp. 2741-2796. Elsevier, Amsterdam.

Magrini S. (2009) Why should we analyse convergence using the distribution dynamics approach?, Scienze Regionali - Italian Journal of Regional Science 8, 5-34.

Mankiw G. N., Romer D. and Weil D. N. (1992) A contribution to the empirics of economic growth, Quarterly Journal of Economics 107, 407-437.

Myrdal G. (1957) Economic Theory and Underdeveloped Regions. Hutchinson, London.

Nadaraya E. A. (1964) On estimating regression, Theory of Probability and Its Applications 1, 141-142.

Pekkala S. (2000) Aggregate economic fluctuations and regional convergence: the Finnish case, 1988-1995, Applied Economics 32, 211-219.

Petrakos G., Rodríguez-Pose A. and Rovolis A. (2005) Growth, integration, and regional disparities in the European Union, Environment and Planning A 37, 1837-1857.

Petrakos G. and Saratsis Y. (2000) Regional inequalities in Greece, Papers in Regional Science 79, 57-74.

Pike A., Rodríguez-Pose A., Tomaney J., Torrisi G. and Tselios V. (2012) In search of the 'economic dividend' of devolution: spatial disparities, spatial economic policy, and decentralisation in the UK, Environment and Planning C 30, 10-28.

Portnov B. A. and Felsenstein D. (2010) On the suitability of income inequality measures for regional analysis: some evidence from simulation analysis and bootstrapping tests, Socio-Economic Planning Science 44, 212-219.

Quah D. T. (1996) Aggregate and regional disaggregate fluctuations, Empirical Economics 21, 137-159.

Quah D. T. (1997) Empirics for Growth and Distribution: Stratification, Polarization, and Convergence Clubs. CEPR Discussion Paper Number 1586. Centre for Economic Policy Research (CEPR), London.

Reichlin L. (1999) Discussion of 'Convergence as distribution dynamics' (by Danny Quah), in BALdwin R., CohEn D., SAPIR A. and Venables A. (Eds) Market Integration, Regionalism, and the Global Economy, pp. 328-335. Cambridge University Press, Cambridge.

Rey S. J. and JanikAS M. V. (2005) Regional convergence, inequality and space, Journal of Economic Geography 5, $155-176$.

Rodríguez-Pose R. and Fratesi U. (2007) Regional business cycles and the emergence of sheltered economies in the southern periphery of Europe, Growth and Change 38, 621-648.

SAlA-I-Martin X. (1996) Regional cohesion: evidence and theories of regional growth and convergence, European Economic Review 40, 1325-1352.

Silverman B. W. (1986) Density Estimation for Statistics and Data Analysis. Chapman and Hall, New York, NY.

Temple J. (1999) The new growth evidence, Journal of Economic Literature 37, 112-156.

Terrasi M. (1999) Convergence and divergence across Italian regions, Annals of Regional Science 33, 491-510.

Tsionas E. G. (2000) Regional growth and convergence: evidence from the United States, Regional Studies 34, $231-238$.

Van Duijn J. J. (1973) An Interregional Model of Economic Fluctuations. Saxon House, Farnborough.

WANG Y. (2004) A nonparametric analysis of the personal income distribution across the provinces and states in the U.S. and Canada, Regional and Sectoral Economic Studies 4, 5-24.

Watson G. S. (1964) Smooth regression analysis, Sankhya A 26, 101-116.

Yамамото D. (2008) Scales of regional income disparities in the USA, 1955-2003, Journal of Economic Geography 8, 79-103.

Zarnowitz V. and Ozyildirim A. (2006) Time series decomposition and measurement of business cycles, trends and growth cycles, Journal of Monetary Economics 53, 1717-1739. 